\title{
Metabolomic Profiling and Genomic Study of a Marine Sponge-Associated Streptomyces sp.
}

Christina Viegelmann ${ }^{1, \dagger}$, Lekha Menon Margassery ${ }^{2, \dagger}$, Jonathan Kennedy ${ }^{2, *}$, Tong Zhang ${ }^{1}$, Ciarán O'Brien ${ }^{2}$, Fergal O'Gara ${ }^{2,3,4,5}$, John P. Morrissey ${ }^{2,3}$, Alan D. W. Dobson ${ }^{2,3}$ and RuAngelie Edrada-Ebel ${ }^{1, *}$

1 Strathclyde Institute of Pharmacy and Biomedical Sciences, University of Strathclyde, The John Arbuthnott Building, 161 Cathedral Street, Glasgow, Scotland G4 0RE, UK; E-Mails: christina.viegelmann@strath.ac.uk (C.V.); tong.zhang.101@strath.ac.uk (T.Z.)

2 Marine Biotechnology Centre, Environmental Research Institute, University College Cork, Lee Road, Cork, Ireland; E-Mails: lekha513@gmail.com (L.M.M.); sarklor@gmail.com (C.O.); f.ogara@ucc.ie (F.O.); j.morrissey@ucc.ie (J.P.M.); a.dobson@ucc.ie (A.D.W.D.)

3 School of Microbiology, University College Cork, Cork, Ireland

4 Biomerit Research Centre, University College Cork, Cork, Ireland

5 School of Biomedical Sciences, Curtin University, Perth 6102, WA, Australia

$\dagger$ These authors contributed equally to this work.

* Authors to whom correspondence should be addressed;

E-Mails: ruangelie.edrada-ebel@strath.ac.uk (R.E.-E.); jonathan.kennedy@ucc.ie (J.K.); Tel.:+44-14-1548-5968 (R.E.-E.); Tel.: +353-214-901-971 (J.K.).

Received: 25 March 2014; in revised form: 7 May 2014 / Accepted: 21 May 2014 /

Published: 2 June 2014

Abstract: Metabolomics and genomics are two complementary platforms for analyzing an organism as they provide information on the phenotype and genotype, respectively. These two techniques were applied in the dereplication and identification of bioactive compounds from a Streptomyces sp. (SM8) isolated from the sponge Haliclona simulans from Irish waters. Streptomyces strain SM8 extracts showed antibacterial and antifungal activity. NMR analysis of the active fractions proved that hydroxylated saturated fatty acids were the major components present in the antibacterial fractions. Antimycin compounds were initially putatively identified in the antifungal fractions using LC-Orbitrap. Their presence was later confirmed by comparison to a standard. Genomic analysis of Streptomyces sp. SM8 revealed the presence of multiple secondary metabolism gene clusters, including a gene cluster for the biosynthesis of the antifungal antimycin family of compounds. The 
antimycin gene cluster of Streptomyces sp. SM8 was inactivated by disruption of the antimycin biosynthesis gene antC. Extracts from this mutant strain showed loss of antimycin production and significantly less antifungal activity than the wild-type strain. Three butenolides, 4,10-dihydroxy-10-methyl-dodec-2-en-1,4-olide (1), 4,11-dihydroxy10-methyl-dodec-2-en-1,4-olide (2), and 4-hydroxy-10-methyl-11-oxo-dodec-2-en-1,4-olide (3) that had previously been reported from marine Streptomyces species were also isolated from SM8. Comparison of the extracts of Streptomyces strain SM8 and its host sponge, H. simulans, using LC-Orbitrap revealed the presence of metabolites common to both extracts, providing direct evidence linking sponge metabolites to a specific microbial symbiont.

Keywords: Streptomyces; Haliclona simulans; metabolomics; antimycin; antifungal; butenolide

\section{Introduction}

Marine sponges are at the forefront of marine natural product discovery. Being sessile animals, they rely mainly on chemical means of defense. Sponges produced $37 \%$ of all novel marine natural products discovered in 2002 [1]. The latest review showed that sponges accounted for $28.6 \%$ of novel compound discoveries from marine sources in 2012, excluding those isolated from sponge-associated microorganisms [2].

Sponges play host to a wide variety of endosymbiotic microorganisms such as bacteria, fungi, yeast, dinoflagellates, diatoms and microalgae [3]. Indeed, some of the compounds previously isolated from sponges have been proven to be products of their endosymbionts [4-7]. This is a distinct advantage in the search for new drugs as this bypasses the supply problem created by the difficulties in procuring sufficient quantities of the desired compounds from marine macroorganisms. In addition, the genome of the microorganism, as well as the culture conditions, can be manipulated to optimize the production of the preferred metabolite.

The bacterial communities of Haliclona sponges from across the globe have been studied [8-11] and these show a diverse range of endosymbionts, many of which produce bioactive metabolites. Of the 52 bacteria isolated from $H$. simulans from the Irish Sea, 29 possessed antibiotic activity against at least one of the bacterial or fungal test strains [8].

A Streptomyces sp., SM8, was isolated from H. simulans collected from Irish waters. Partial 16S rRNA sequencing indicated that this strain bore $100 \%$ similarity to Streptomyces violascens XSD-115 and several other Streptomyces species [8]. Other strains of S. violascens have been reported to produce antibiotics such as actinomycin D and actinomycin $\mathrm{X}_{2}(\mathrm{~V})$ [12] (Figure 1), protease inhibitors such as trypsin and chymotrypsin inhibitors [13], and 3 $\beta$-hydroxysteroid oxidase [14].

Metabolomics and genomics are two complementary platforms in systems biology. Genomics details the genotype of the organism whereas metabolomics reveals its phenotype. While the former is widely established, the latter is a relatively new field that is still evolving as both technology and various methodologies are improved and refined $[15,16]$. Although both platforms are used in natural product discovery, relatively few studies have used both approaches. Seipke et al. used a combination 
of genomics and chemical isolation to characterize antifungal compounds from actinomycetes $[17,18]$ and genomic and chemical techniques have also been used to study Salinispora tropica, a marine actinomycete, leading to the structural elucidation of salinilactam A and providing a greater depth of information on the biosynthetic capabilities of S. tropica [19]. The dual approach of metabolomics and genomics was used to analyze SM8 in order to facilitate the identification and isolation of bioactive compounds with a particular focus on antifungal metabolites.

Figure 1. Structures of actinomycin D, actinomycin X2 and salinilactam, isolated from strains of Streptomyces.
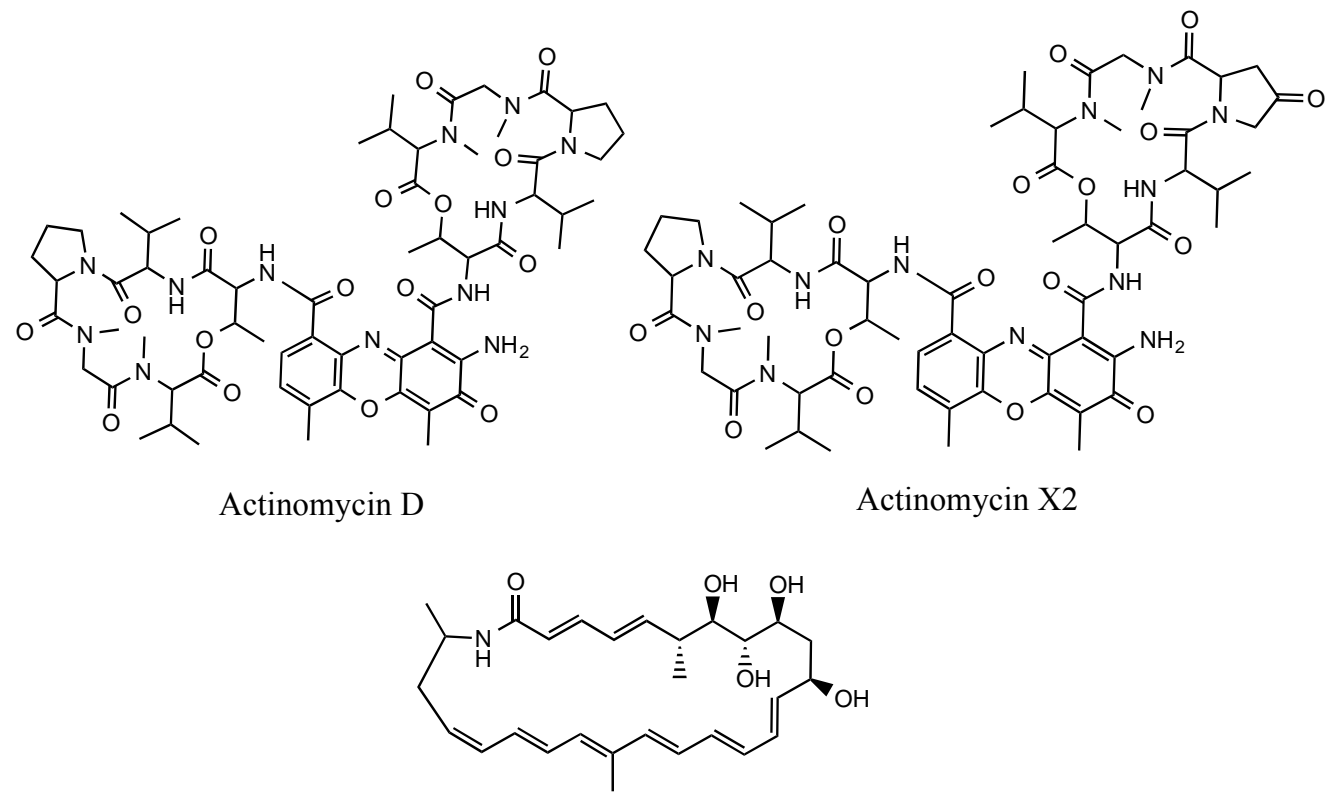

Salinilactam

Metabolomic techniques such as nuclear magnetic resonance (NMR) spectroscopy and liquid chromatography-high resolution mass spectrometry (LC-HRMS) were applied in the preliminary screening of metabolites produced by Streptomyces strain SM8. These two complementary analytical techniques allow the rapid identification of classes of compounds present in the samples as well as the putative identification of specific compounds [20,21]. However, although LC-HRMS is extremely sensitive and can detect compounds present in very low quantities, there are certain classes of compounds that cannot be detected by the mass spectrometer, the reason being that they are unable to be ionized. NMR, on the other hand, has no separation step and therefore provides a snapshot of the metabolome of the sample. It is less sensitive than MS but is more reproducible and has no discrimination in detection depending on the concentration of the sample and the power of the spectrometer. Both methods of analysis can be applied in the structural elucidation of compounds.

Extracts of Streptomyces strain SM8 possessed antifungal and antibacterial activity. The goal of this study was to use the dual approach of metabolomics and genomics to analyze Streptomyces strain SM8 in order to facilitate the identification and isolation of bioactive compounds with a particular focus on antifungal metabolites. Metabolomics was further applied in the comparison of the extract of Streptomyces strain SM8 with that of its host sponge to determine whether compounds produced by the bacteria could be found in the sponge. 


\section{Results and Discussion}

Streptomyces strain SM8, isolated from the sponge $H$. simulans, was cultured on two types of media: oatmeal media (OM-SW) and starch-yeast extract-peptone (SYP-SW) media. The crude extracts, prepared by solid phase extraction with Amberlite ${ }^{\circledR}$ XAD-16 resin (Rohm and Haas Company, Philadelphia, PA, USA), exhibited activity against Bacillus subtilis, Pseudomonas aeruginosa, Candida albicans, C. glabrata, Saccharomyces cerevisiae, Aspergillus fumigatus and Kluyveromyces marxianus.

\subsection{Genomic Analysis of Streptomyces Strain SM8}

The genome sequence of Streptomyces strain SM8 was determined by Roche 454 pyrosequencing. Following assembly, the draft genomic sequence (Table 1) consisted of 534 contigs with a total size of $7.2 \mathrm{Mb}$ in and a GC content of $73 \%$. A total of 6647 protein coding genes were annotated, including 31 putative non-ribosomal peptide synthetase (NRPS) modules and 25 polyketide synthase (PKS) modules were identified in the draft genome in addition to other genes predicted to be involved in the biosynthesis of secondary metabolites. The genome sequence is deposited at GenBank with accession number PRJNA180938.

Table 1. Genomic data for Streptomyces strain SM8.

\begin{tabular}{cc}
\hline Genomic data for Streptomyces strain SM8 \\
\hline Genome size & $7.155 \mathrm{Mb}$ \\
Contigs & 534 \\
GC content & $73 \%$ \\
Gene count & 6722 \\
Protein coding genes & 6647 \\
RNA genes & 75 \\
NRPS modules & 31 \\
PKS modules & 25 \\
\hline
\end{tabular}

Secondary metabolism gene clusters for the known antifungal metabolites antimycin and candicidin (Figure 2) were identified in the Streptomyces SM8 genome. The putative candicidin gene cluster was spread over 18 contigs in the assembly, however analysis of the cluster by comparison to known polyene PKS clusters confirmed that all the predicted biosynthesis genes were present. The antimycin gene cluster was also found to be intact by comparison to the published cluster from Streptomyces albus sp. S4 [18]. Other predicted secondary metabolism gene clusters present in the Streptomyces SM8 genome include a large NRPS gene cluster, similar to a linear gramicidin biosynthesis cluster, encoding a predicted 16 amino acid linear peptide and additional smaller NRPS, PKS and hybrid secondary metabolism gene clusters. In addition to the gene clusters for modular PKS and NRPS the genome was also found to contain genes and gene clusters predicted to be involved in the biosynthesis of terpenes, ribosomally encoded peptide antibiotics and siderophores. 
Figure 2. Structures of antimycin A1 and candicidin.

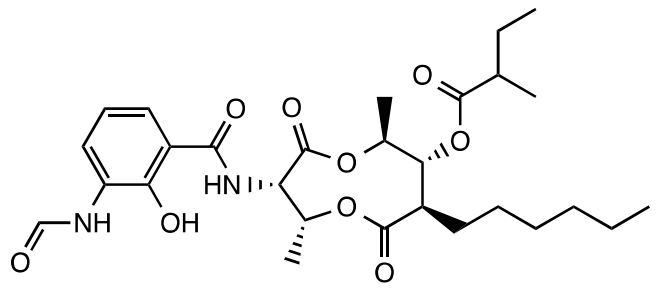

Antimycin A1a

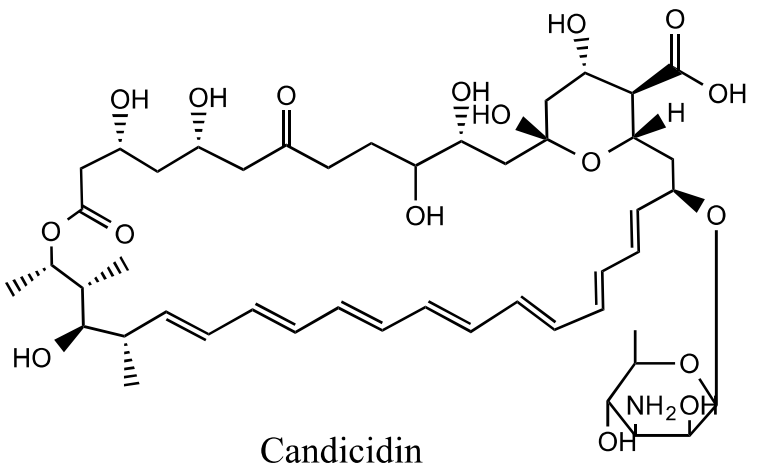

Candicidin

\subsection{Identification of Bioactive Metabolites from Streptomyces Strain SM8}

\subsubsection{Chemical Analysis of Antibacterial and Antifungal Fractions from Small-Scale SM8 Extract}

Crude extract, prepared by solid phase extraction with Amberlite ${ }^{\circledR}$ XAD-16 resin (Rohm and Haas Company, Philadelphia, PA, USA), from batch cultures of Streptomyces strain SM8 was fractionated with water and methanol using reverse phase medium pressure liquid chromatography (MPLC). Fractions were assessed for antimicrobial activities against C. albicans and B. subtilis, the fungal and bacterial strains that were most sensitive to the crude extract. The minimum inhibitory concentrations (MICs) of the most active fractions are shown in Table 2.

Table 2. MICs of the most active fractions from the SM8 extract.

\begin{tabular}{cccc}
\hline Pooled Fraction & Yield $(\mathbf{m g})$ & B. subtilis $\mathbf{M I C}\left(\boldsymbol{\mu g} \cdot \mathbf{m L}^{\mathbf{- 1}}\right)$ & C. albicans $\mathbf{M I C}\left(\boldsymbol{\mu g} \cdot \mathbf{m L}^{\mathbf{- 1}}\right)$ \\
\hline $221-226$ & 6.5 & 7.42 & 240 \\
$227-230$ & 9.5 & 9.40 & 210 \\
$239-242$ & 9.1 & 400 & 80 \\
$243-248$ & 13.0 & 400 & 90 \\
\hline
\end{tabular}

HRESIMS data of the semi-purified fractions 221-230 revealed the occurrence of two major inseparable components with ion peaks at $\mathrm{m} / \mathrm{z} 375.2757 / 417.3228[\mathrm{M}-\mathrm{H}]^{-}$in negative mode and $\mathrm{m} / \mathrm{z}$ 377.2898/419.3668 $[\mathrm{M}-\mathrm{H}]^{+}$in positive mode with the molecular formulas of $\mathrm{C}_{20} \mathrm{H}_{40} \mathrm{O}_{6}$ and $\mathrm{C}_{23} \mathrm{H}_{46} \mathrm{O}_{6}$, respectively. Both ion peaks designated with $\mathrm{RDB}$ of 1.0 indicated the aliphatic and polyhydroxylated lipid nature of the structure. The ${ }^{1} \mathrm{H}$ NMR spectrum in DMSO- $d_{6}$ exhibited that the major compounds in the antibacterial fractions were indeed polyhydroxylated saturated fatty acids. Peaks belonging to terminal methyl groups $\left(\delta_{\mathrm{H}} 0.80\right.$ to 1.00$)$, aliphatic $\mathrm{CH}_{2}$ groups $\left(\delta_{\mathrm{H}} 1.24\right.$ to 1.30$)$, hydroxyl-bound $\mathrm{CH}\left(\delta_{\mathrm{H}} 3.00\right.$ and 4.50$)$, and the $\mathrm{CH}_{2}$ group attached to the acid terminus $\left(\delta_{\mathrm{H}} 2.19\right.$ to 2.80) are characteristic of polyhydroxylated saturated fatty acids. The oxymethine protons also corresponded to peaks resonating between 60 and $75 \mathrm{ppm}$ as shown by its ${ }^{13} \mathrm{C}$ NMR spectrum (see Supplementary Information). The presence of two polyhydroxylated saturated fatty acid congeners (Figure 3) at a ratio of 1:1 was confirmed by their extracted ion chromatograms (Figure 4). Due to the overlapping carbon resonances of the oxymethine, long chain methylene and terminal methyl groups, it was not possible to deduce unambiguously the position of the hydroxyl groups by $\mathrm{HMBC} \mathrm{MS}^{n}$ fragmentation in the positive mode revealed the position of the hydroxyl units on the alkyl chain 
through homolytic bond cleavage as shown in Figures 5 and 6. This was then unambiguously supported by the COSY NMR data (Figure 7). The two polyhydroxylated saturated fatty acids were then elucidated as 3,6,8,11-tetrahydroxy-16,17-dimethyloctadecanoic acid and 2,8,10,19-tetrahydroxy-18methyldocosanoic acid, respectively. When compared to the $c a$. 3-4 ppm proton chemical shifts of oxymethine hydrogens, the proton resonance of the terminal 2-hydroxybutanoic acid moiety was deshielded to 4-5 pm which was comparable to those of the glykenin antibiotics (Figure 8) [22].

Figure 3. Structure of polyhydroxylated saturated fatty acids found in fractions 221-230.<smiles>CC(C)C(C)CCCCC(O)CCC(O)CCCC(O)CC(=O)O</smiles>

3,6,8,11-tetrahydroxy-16,17-dimethyloctadecanoic acid Chemical Formula: $\mathrm{C}_{20} \mathrm{H}_{40} \mathrm{O}_{6}$

Exact Mass: 376.2825<smiles>CCCC(O)C(C)CCCCCCCC(O)CC(O)CCCCCC(O)C(=O)O</smiles>

2,8,10,19-tetrahydroxy-18-methyldocosanoic acid Chemical Formula: $\mathrm{C}_{23} \mathrm{H}_{46} \mathrm{O}_{6}$

Exact Mass: 418.3294

Figure 4. Extracted ion chromatograms and high resolution mass spectra of fractions 221-230.

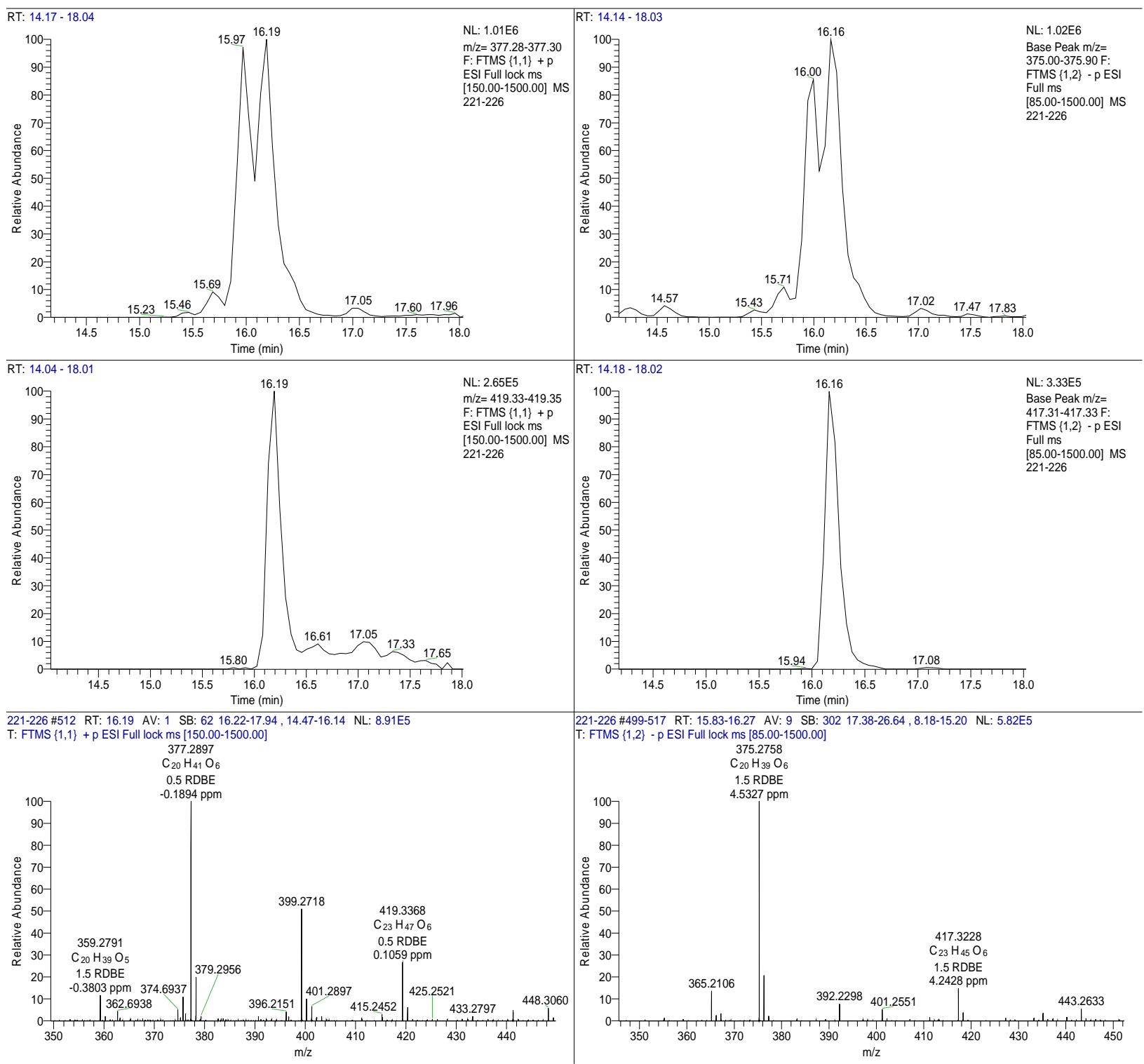


Figure 5. $\mathrm{MS}^{n}$ fragmentation of the polyhydroxylated lipids found in fractions 221-230. Source fragmentation data in the positive mode summarizing the $\mathrm{MS}^{n}$ ion peaks for $\mathrm{m} / \mathrm{z} 377.2898$ (red) and 419.3668 (blue).

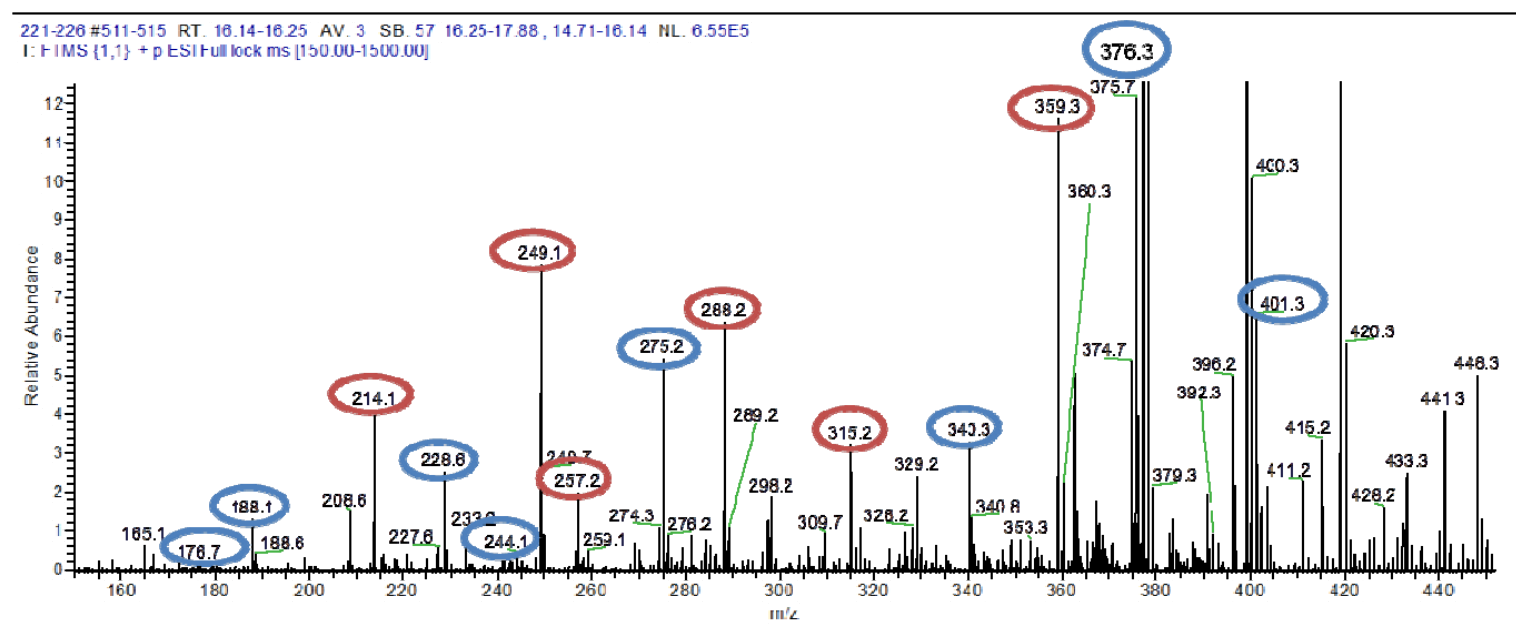

Figure 6. Proposed fragmentation pathway for 3,6,8,11-tetrahydroxy-16,17-dimethylocta decanoic acid $\left(\mathrm{C}_{20} \mathrm{H}_{40} \mathrm{O}_{6}\right)$ and 2,8,10,19-tetrahydroxy-18-methyldocosanoic acid $\left(\mathrm{C}_{23} \mathrm{H}_{46} \mathrm{O}_{6}\right)$.
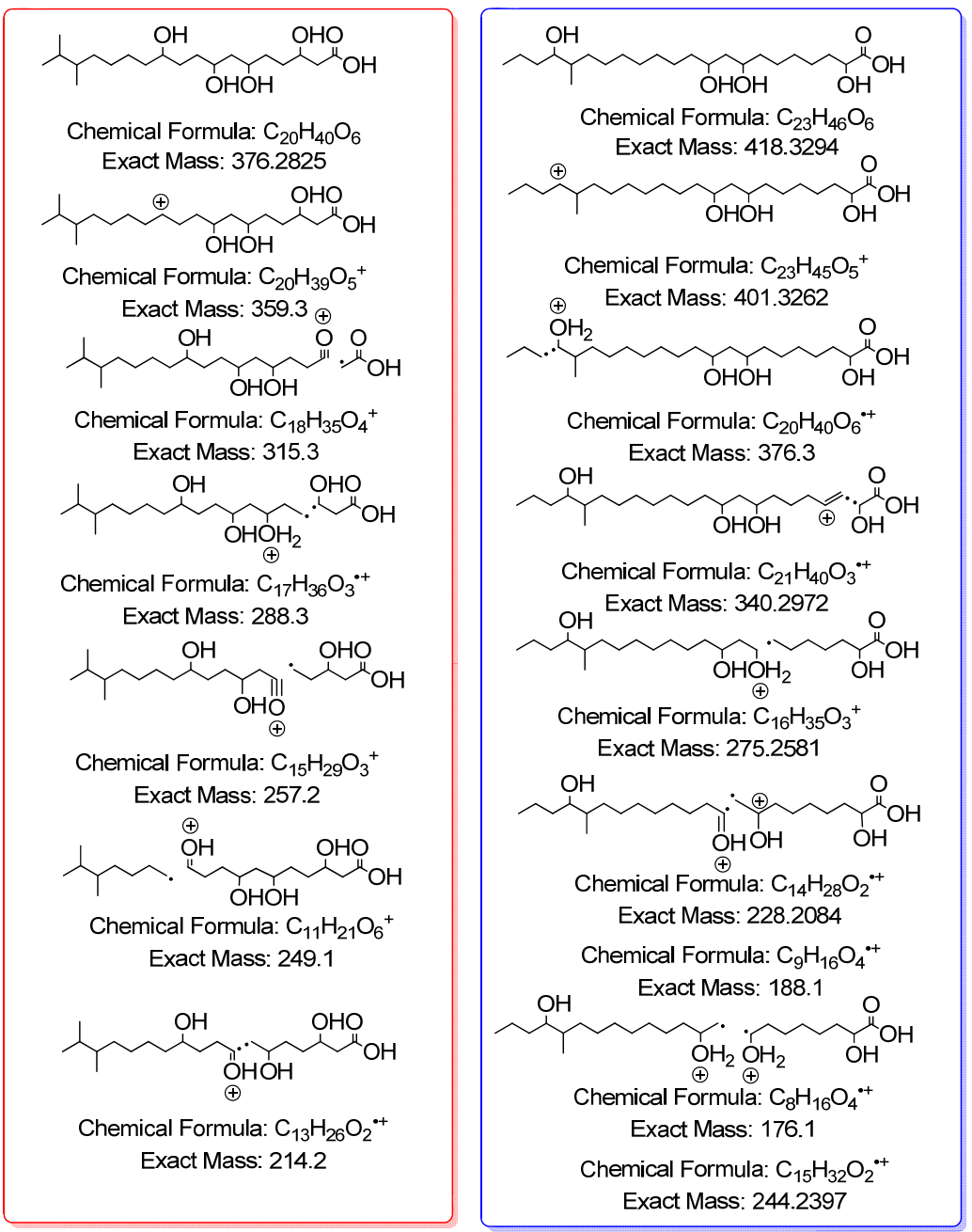
Figure 7. ${ }^{1} \mathrm{H}-\mathrm{COSY}$ NMR of fractions 221-226 and 227-230, which were the most potent against B. subtilis. (Full spectral data in Supplementary Information).
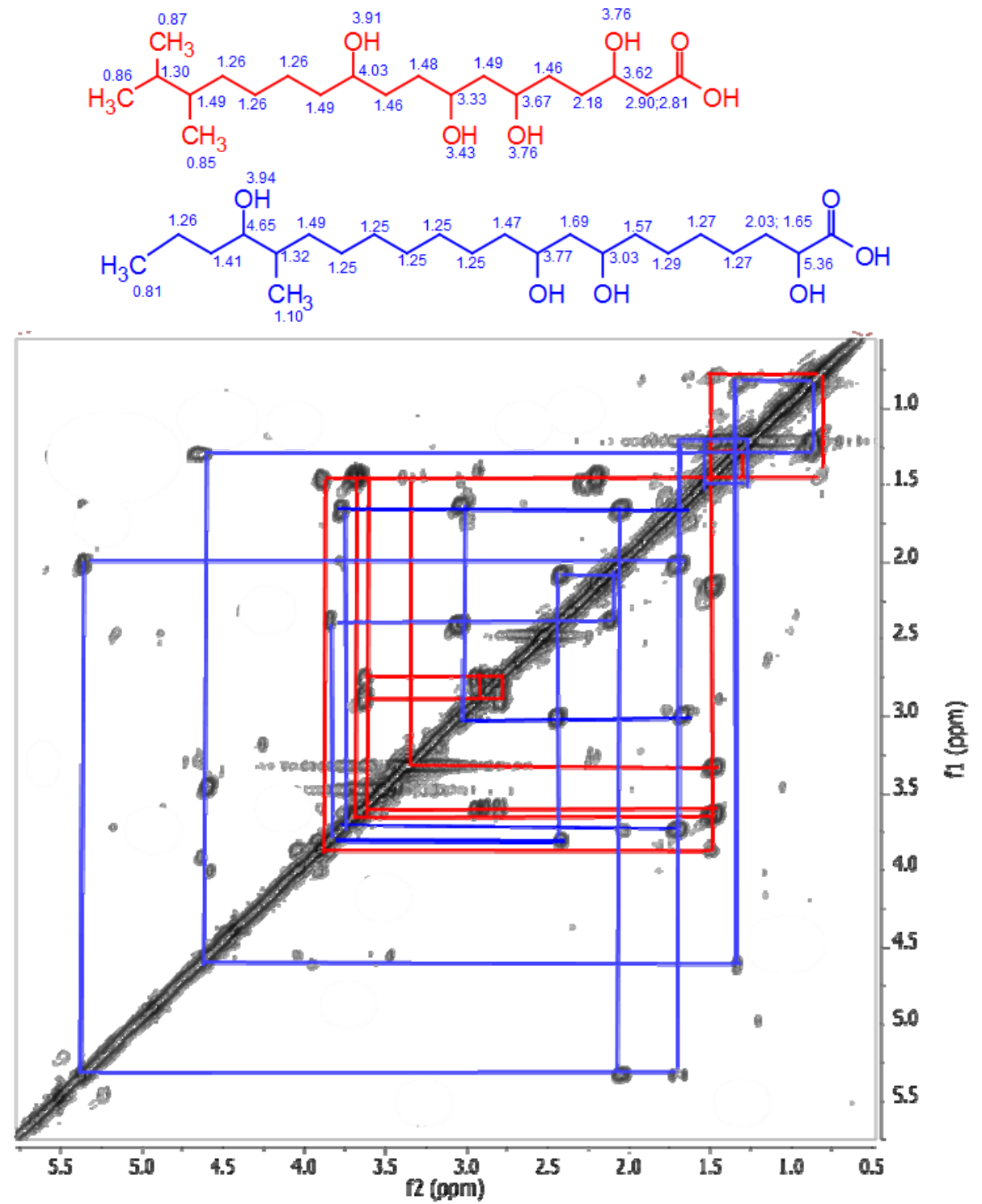

Aside from Streptomyces strain SM8, other species of Streptomyces such as S. scabies primarily produce saturated fatty acids rather than unsaturated fatty acids [23]. Hydroxy saturated fatty acids have previously been reported to have activity against some strains of fungi [24], whereas other saturated fatty acids have been proven to inhibit the growth of methicillin-resistant Staphylococcus aureus [25]. Polyhydroxy saturated fatty acids have previously been isolated from fungi such as Ulocladium botrytis and Haematomma ventosum [26,27]. They have also been found as degradation products of guanidylfungin A and B (Figure 8), metabolites of S. hygroscopicus that are active against fungi and Gram-negative bacteria [28,29]. The tetrahydroxy saturated fatty acids also comprise the aglycone portion of the deacetyl glykenins A-C (Figure 8) which are glycosidic antibiotics produced by Basidiomycetes sp. [22]. 
Figure 8. Structures of the guanidylfungins and deacetyl glykenins.

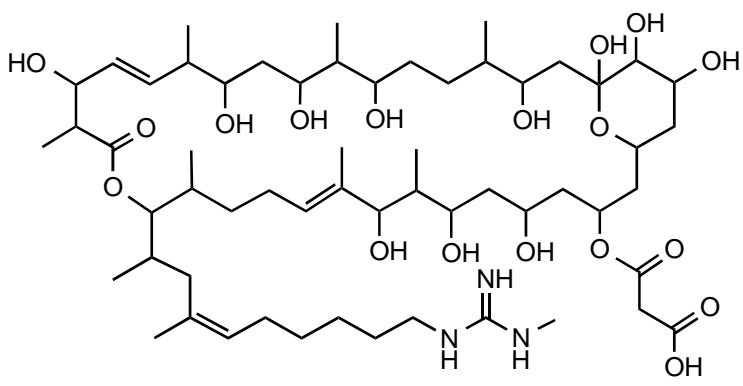

Guanidylfungin A

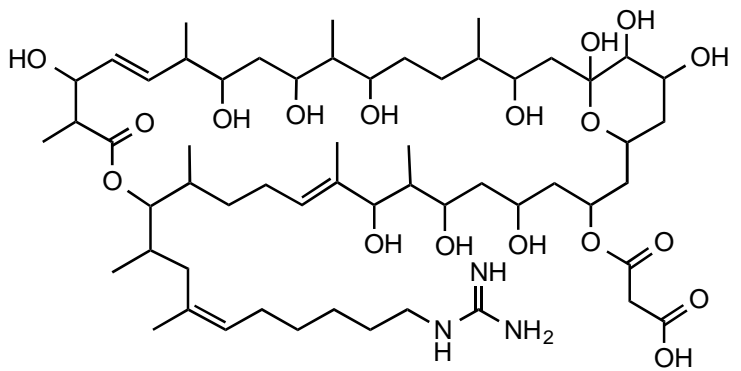

Guanidylfungin B

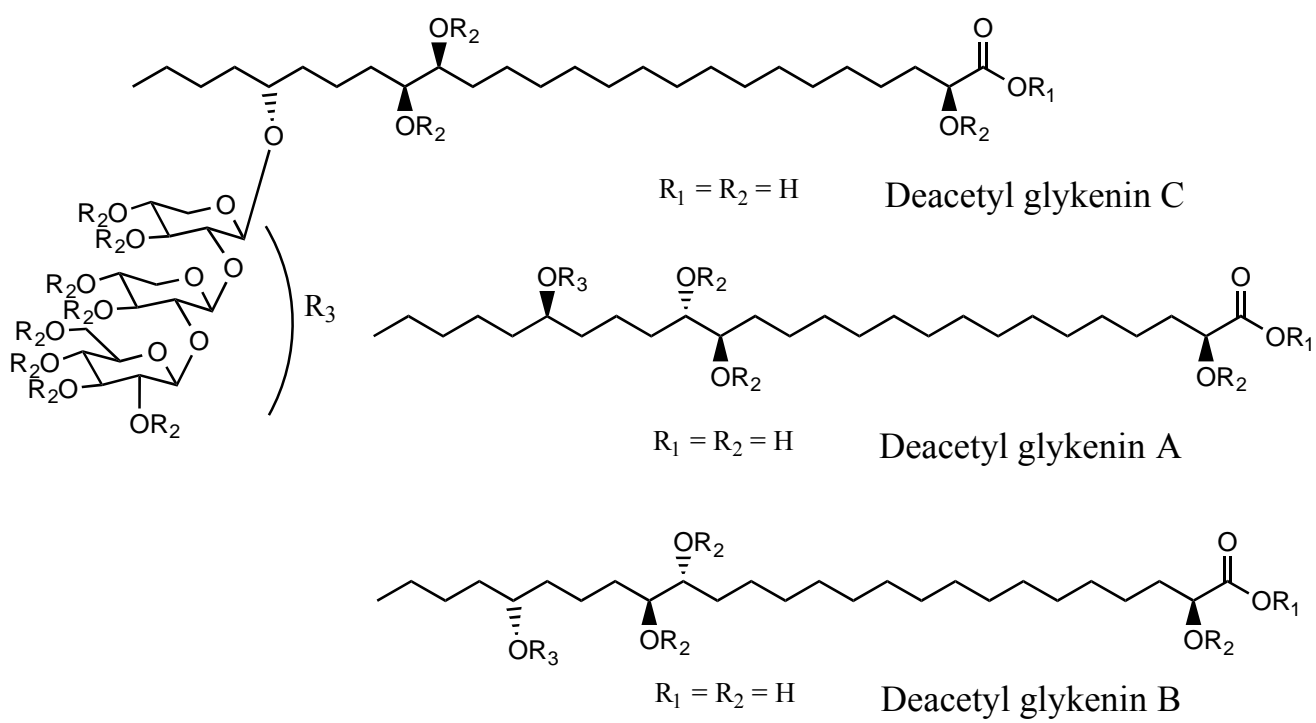

The active fractions were also analyzed by LC-Orbitrap and based on accurate mass $( \pm 3 \mathrm{ppm})$, we searched the Dictionary of Natural Products (DNP) database to putatively identify metabolites that had previously been reported as products of Streptomyces sp. As seen in Table 3, the predominant identified compounds were members of the antimycin family.

Table 3. Streptomyces metabolites dereplicated from active fractions using the DNP 2012 database. Metabolites in this table are limited to those with the largest peak area and from the biological source Streptomyces sp. Kitamycin also belongs to the antimycin family of antifungal compounds.

\begin{tabular}{|c|c|c|c|c|c|}
\hline Fraction & & $m / \mathbf{z}$ & RT (min) & Name & Formula \\
\hline \multirow{2}{*}{$221-226$} & {$[\mathrm{M}+\mathrm{H}]^{+}$} & 465.2235 & 19.53 & Kitamycin A or B & $\mathrm{C}_{23} \mathrm{H}_{32} \mathrm{~N}_{2} \mathrm{O}_{8}$ \\
\hline & {$[\mathrm{M}-\mathrm{H}]^{-}$} & 519.2353 & 19.43 & Antimycin A3 or A7 & $\mathrm{C}_{26} \mathrm{H}_{36} \mathrm{~N}_{2} \mathrm{O}_{9}$ \\
\hline \multirow{2}{*}{$227-230$} & {$[\mathrm{M}+\mathrm{H}]^{+}$} & 535.2652 & 20.70 & \multirow{2}{*}{ Antimycin A2, A8, A11 or A17 } & \multirow{2}{*}{$\mathrm{C}_{27} \mathrm{H}_{38} \mathrm{~N}_{2} \mathrm{O}_{9}$} \\
\hline & {$[\mathrm{M}-\mathrm{H}]^{-}$} & 533.2512 & 20.67 & & \\
\hline \multirow{2}{*}{$239-242$} & {$[\mathrm{M}+\mathrm{H}]^{+}$} & 521.2493 & 24.34 & \multirow{2}{*}{ Antimycin $\mathrm{A} 3$ or $\mathrm{A} 7$} & \multirow{2}{*}{$\mathrm{C}_{26} \mathrm{H}_{36} \mathrm{~N}_{2} \mathrm{O}_{9}$} \\
\hline & {$[\mathrm{M}-\mathrm{H}]^{-}$} & 519.2352 & 24.25 & & \\
\hline \multirow{2}{*}{$243-248$} & {$[\mathrm{M}+\mathrm{H}]^{+}$} & 535.2650 & 25.63 & Antimycin A2, A8, A11 or A17 & $\mathrm{C}_{27} \mathrm{H}_{38} \mathrm{~N}_{2} \mathrm{O}_{9}$ \\
\hline & {$[\mathrm{M}-\mathrm{H}]^{-}$} & 519.2352 & 24.25 & Antimycin A3 or A7 & $\mathrm{C}_{26} \mathrm{H}_{36} \mathrm{~N}_{2} \mathrm{O}_{9}$ \\
\hline
\end{tabular}




\subsubsection{Deletion of Antimycin Gene Cluster from Streptomyces Strain SM8}

Genomic analysis of Streptomyces strain SM8 revealed the presence of an antimycin biosynthetic gene cluster with high similarity to and the same gene organization as that identified from Streptomyces albus S4 [18]. In order to determine the contribution of antimycin to the total antifungal activity of the strain this gene cluster was inactivated. The antC gene, encoding a NRPS central to the antimycin biosynthesis pathway, was deleted from the strain (Figure 9). The deletion in the resulting strain, SM8- $\Delta$ antC, was confirmed by PCR.

Figure 9. Disruption of antimycin biosynthesis cluster in Streptomyces strain SM8 by deletion of antC. Panel A: Characterized antimycin gene cluster containing genes antA to antO. Genes are color coded according to predicted roles in pathway; regulation-red; NRPS and PKS scaffold biosynthesis-green; FSA starter unit biosynthesis-blue; post-PKS/NRPS tailoring - pink; PKS extender unit supply_-grey. The antC gene encodes an NRPS gene essential for antimycin biosynthesis. To disrupt the antimycin gene cluster regions from upstream and downstream of the antC gene (shown underlined) were PCR amplified and cloned into the vector pKC1139 to produce pKC1139A1A2. This plasmid was introduced into Streptomyces strain SM8 in order to delete the antC gene as described; Panel B: antimycin gene cluster following deletion of a $3 \mathrm{~kb}$ part of the antC gene; Panel C: Antifungal bioassay of antC mutant strain. Antifungal activities of a dilution series of extracts (rows 1-4) were determined against C. albicans; 1-WT extract grown in OM-SW broth; 2- $-\Delta a n t C$ extract grown in OM-SW broth; 3-WT extract from SYP-SW broth; 4- $\Delta$ antC extract from SYP-SW; column G—no extract; column S—no inoculum.

A

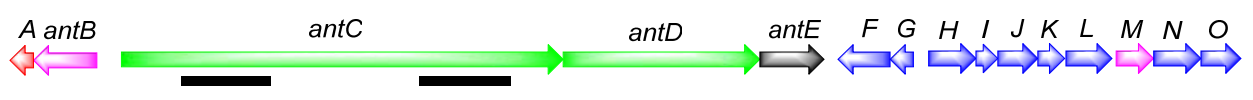

B

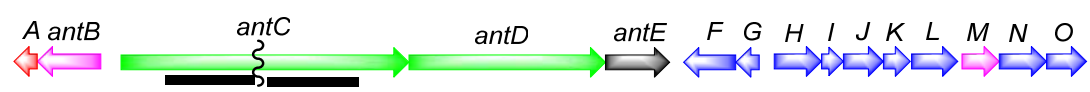

C

\section{G $\mathbf{S}$}

1

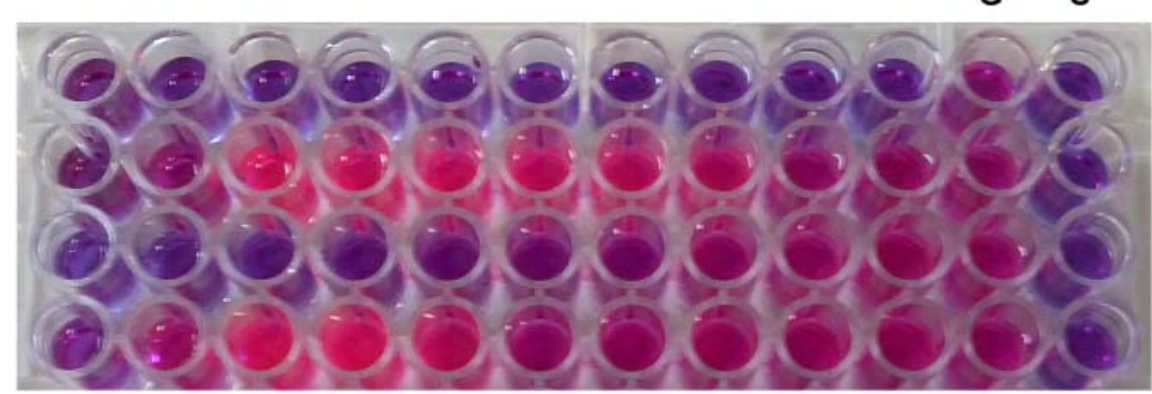

Both the mutant (SM8- $\Delta a n t C)$ and wild-type SM8 were cultured on OM-SW and SYP-SW and the resulting extracts were subjected to bioassays. Extracts from the SM8- $\Delta$ antC mutant strain were shown to have $\sim 32$-fold less antifungal activity than the wild-type SM8 (Figure 9). LC-Orbitrap analysis of 
the culture extracts in comparison to an antimycin A standard mixture (Sigma, St. Louis, MO, USA) confirmed the presence of antimycins A1, A2, A3 and A4 in the wild-type but not in the mutant SM8 strain (Figure 10). Although the datasheet of Sigma-Aldrich (St. Louis, MO, USA) claimed it only contains antimycins A1-A4, A5 and A6 were also seen in the LC-MS. The OM-WT extract contained compounds with the same $\mathrm{m} / \mathrm{z}$ and retention time as the standard, as evidenced in Figure 10, in addition to other compounds that had the same $\mathrm{m} / \mathrm{z}$ but different retention times. It is likely that these are additional isomers of antimycin, not present in the standard, as the majority of these contain the fragment ion at $m / z 265.081[\mathrm{M}+\mathrm{H}]^{+}$, which is characteristic of the antimycins. The SYP-WT extract did not contain any antimycin compounds that were identical to those present in the standard; however compounds identical to the putative additional antimycins present in the OM-WT extract were detected. The extracts from the SM8- $\Delta a n t C$ strain were found to contain no traces of antimycin-like compounds. The chromatograms are shown in Figure 10, a summary of the antimycin metabolites identified is shown in Table 4, and the structures of antimycins A1-A4 together with the fragmentation of the dilactone ring of antimycin A1a to generate the fragment ion with an $\mathrm{m} / \mathrm{z}$ of 265.081 are shown in Figure 11. Using a single point calibration assay, total antimycin content can be quantified from the summation of peak areas of extracted ion peaks of detected antimycin congeners in comparison to $1 \mathrm{mg} / \mathrm{mL}$ concentration of standard antimycin mixture sample. OM-WT and SYP-WT extract had a total antimycin content of 161.61 and $15.10 \mu \mathrm{g} / \mathrm{mL}$, respectively as based on peaks exhibiting a fragment ion at $\mathrm{m} / \mathrm{z} 265.081$.

Figure 10. Analyses of antimycin production in wild-type and mutant strains. Extracts were analyzed by LC-Orbitrap and compared to the antimycin A standard. Although the standard is alleged to contain antimycin A1 to A4, peaks corresponding to antimycin A5 and A6 were also identified. The samples are as follows: antimycin A standard (dark blue); extract from SM8 WT grown in OM-SW (red); extract from SM8- $\Delta a n t C$ mutant grown in OM-SW (green); extract from SM8 WT grown in SYP-SW (pink); extract from SM8- $\Delta a n t C$ mutant grown in SYP-SW (light blue).

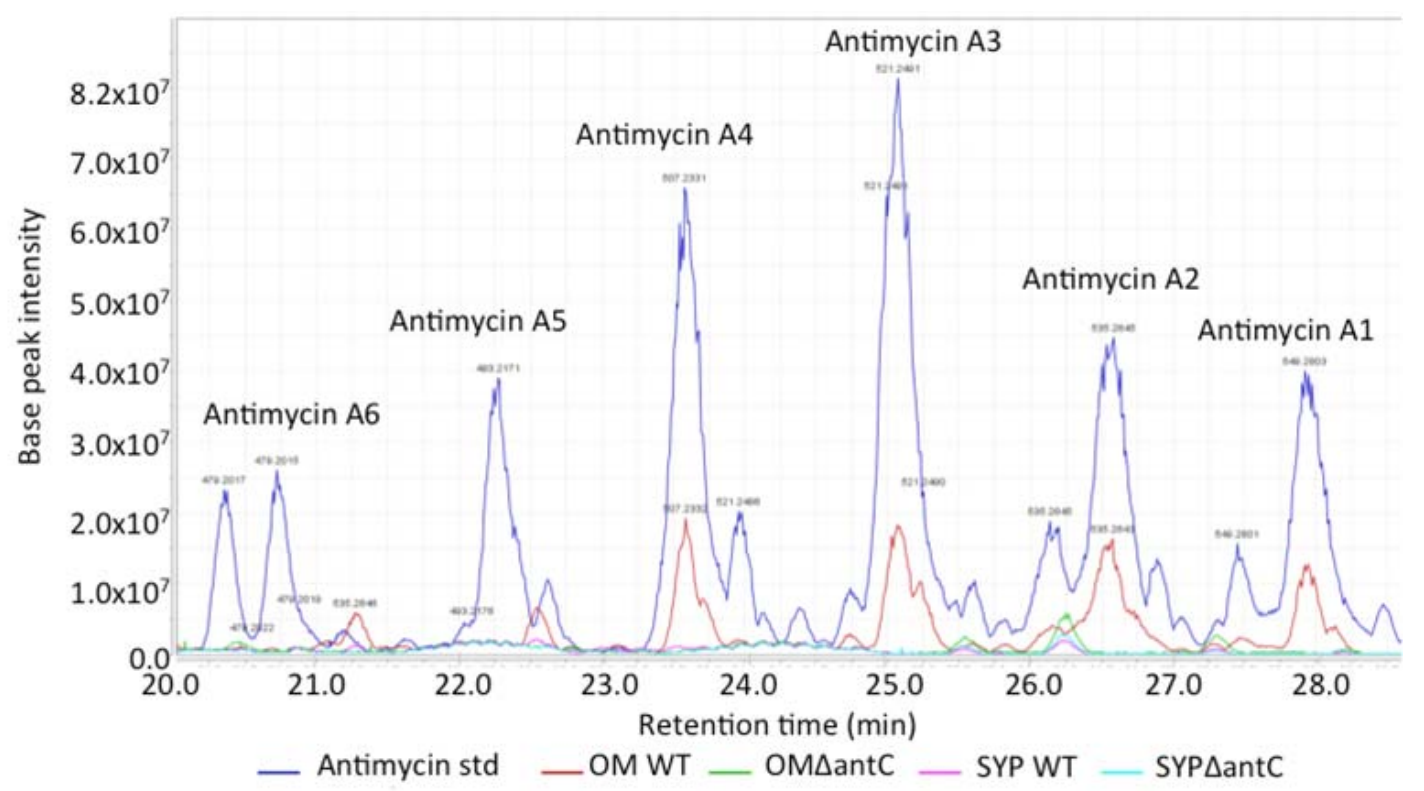


Table 4. Identification of antimycins in the SM8 extracts. Compounds were identified as antimycins based on comparison to authentic antimycin standards (STD). Compounds with identical $\mathrm{m} / \mathrm{z}$ values and based on the presence of the characteristic fragment ion at $\mathrm{m} / \mathrm{z} 265.081[\mathrm{M}+\mathrm{H}]^{+}$(indicated by + ) were putatively identified as antimycins. n.d $(\mathrm{m} / \mathrm{z} 265$ not detected).

\begin{tabular}{|c|c|c|c|c|c|c|c|c|c|c|c|}
\hline \multirow{2}{*}{$\begin{array}{c}\text { Antimycin } \\
\text { A }\end{array}$} & \multirow{2}{*}{$\begin{array}{c}m / \mathbf{z} \\
{[\mathbf{M}+\mathbf{H}]^{+}}\end{array}$} & \multicolumn{2}{|c|}{ STD } & \multicolumn{2}{|c|}{ OM WT } & \multicolumn{2}{|c|}{ OM antC } & \multicolumn{2}{|c|}{ SYP WT } & \multicolumn{2}{|c|}{ SYP antC } \\
\hline & & RT & $m / z 265$ & RT & $m / z 265$ & RT & $m / z 265$ & RT & $m / z 265$ & RT & $m / z 265$ \\
\hline \multirow{2}{*}{1} & \multirow{2}{*}{549.280} & & & 22.54 & + & & n.d & 22.56 & + & & n.d \\
\hline & & 27.92 & + & 27.95 & + & & n.d & & & & n.d \\
\hline \multirow{4}{*}{2} & \multirow{4}{*}{535.264} & & & 19.97 & + & & n.d & 20.90 & + & & n.d \\
\hline & & & & 21.26 & + & & n.d & 21.27 & + & & n.d \\
\hline & & 25.61 & + & 25.23 & + & & n.d & & & & n.d \\
\hline & & 26.58 & + & 26.58 & + & & n.d & & & & n.d \\
\hline \multirow{3}{*}{3} & \multirow{3}{*}{521.249} & & & 19.77 & + & & n.d & 19.65 & + & & n.d \\
\hline & & 23.95 & + & 23.68 & + & & n.d & & & & n.d \\
\hline & & 25.08 & + & 25.07 & + & & n.d & & & & n.d \\
\hline 4 & 507.233 & 23.58 & + & 23.59 & + & & n.d & & & & n.d \\
\hline 5 & 493.217 & 22.27 & + & & n.d & & n.d & & & & n.d \\
\hline \multirow{2}{*}{6} & \multirow{2}{*}{479.202} & 20.35 & + & & n.d & & n.d & & & & n.d \\
\hline & & 20.72 & + & & n.d & & n.d & & & & n.d \\
\hline
\end{tabular}

Figure 11. Antimycins A1 to A4. The fragmentation of the ring to generate the 265 $[\mathrm{M}+\mathrm{H}]^{+}$ion, common to antimycins $\mathrm{A} 1 \mathrm{a} / \mathrm{b}$ to $\mathrm{A} 4 \mathrm{a} / \mathrm{b}$, is also shown.

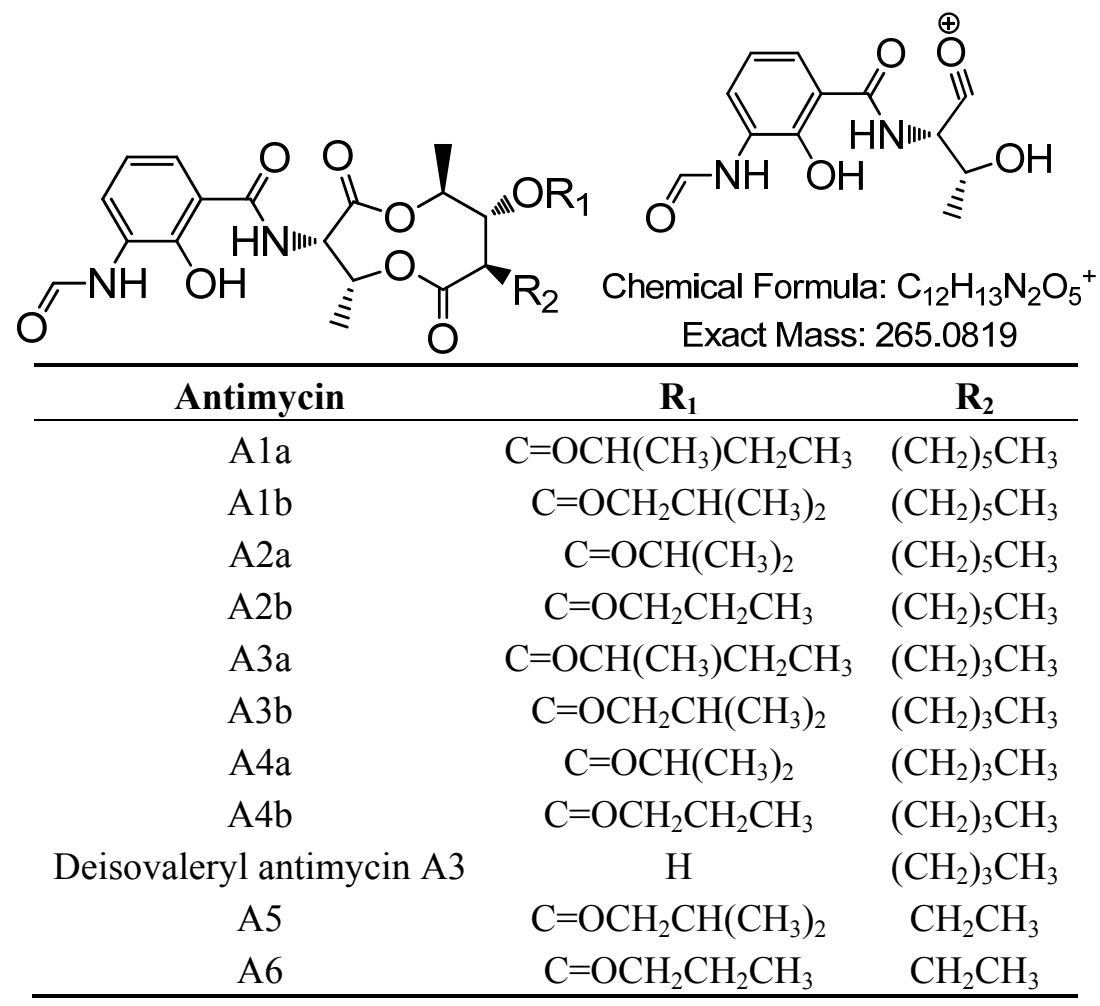

Antimycin A was first isolated from an unknown soil Streptomyces sp. [30]. It was discovered to be a mixture of four components, named A1 to A4, which were then purified and characterized. 
Antimycin A3 was found to be the most active component [31,32] although this appears to be due to its diffusion coefficient in agar [33]. Since then, many other compounds falling under the antimycin A family have been isolated from other Streptomyces species [34]. These compounds possess antifungal activity and act by blocking the electron transport chain via inhibition of the cytochrome $b c_{1}$ complex. Gram positive bacteria lack this antimycin sensitive site and hence are unaffected by antimycin A [35]. In the course of this study it was noted that the antC mutant strain had reduced antibacterial activity against $P$. aeruginosa PAO1, but not against any of the other bacterial strains tested. This was investigated further and it was discovered that the purified antimycin standard mixture had a previously unreported activity antibacterial activity against $P$. aeruginosa PAO1 with an MIC of $0.05 \mathrm{mg} \cdot \mathrm{mL}^{-1}$. Aside from being a well-known antifungal, antimycin $\mathrm{A}$ is also a fish toxicant [36], and therefore could be of value to a sponge when produced by an endosymbiont.

The optimum conditions for antimycin production have previously been studied in S. antibioticus. Antimycin production in S. antibioticus has been shown to increase when the tryptophan concentration in the media was increased to $2 \mathrm{mg} \cdot \mathrm{mL}^{-1}$ after which there was decreased antimycin production. It has been proven that the benzene ring of DL-tryptophan is incorporated into antimycin A [37]. More recent studies have shown that tryptophan is the precursor from which the 3-formamidosalicylic acid (FSA) moiety is formed. The dilactone core is then created by sequential elongation with threonine and pyruvate, followed by cyclization to close the ring [38]. In this study, tryptophan was present in the yeast extract that was a component of the SYP-SW media, but to what extent this affected antimycin A production in SM8 is unknown. OM-SW media was found to be optimum for antimycin A production, however tryptophan was not found in the mass spectrum of the blank oatmeal media. The regulation of expression of antimycin gene clusters is complex, involving a pathway specific sigma factor, present in the gene cluster (antA) which controls genes for the production of the FSA moiety with as yet unknown factors controlling expression of the other biosynthesis genes [39]. While OM-SW media is certainly the media of choice for antimycin production, other media, such as SYP-SW may be preferred for isolation of antifungal compounds other than the antimycins. These results highlight the advantages of using both genomics and metabolomics as complementary techniques. The presence of the antimycin biosynthetic gene cluster in the SM8 genome facilitated the identification of these compounds in the extracts and metabolomic analyses have demonstrated the differences in the production of metabolites depending on the growth conditions used. Future work will correlate gene expression and metabolomics data.

\subsubsection{Isolation of Compounds from Large-Scale Cultures of Streptomyces SM8}

A larger scale culture of SM8 grown on oatmeal media was extracted in order to isolate compounds. Although the antimycins were not obtained as pure compounds, LC-HRMS data indicated that the presence of antimycins in the fractions correlated with antifungal activity.

Three butenolides (Figure 12) were obtained that had previously been isolated from marine Streptomyces sp. [40]. These were identified as 4,10-dihydroxy-10-methyl-dodec-2-en-1,4-olide (1), 4,11-dihydroxy-10-methyl-dodec-2-en-1,4-olide (2), and 4-hydroxy-10-methyl-11-oxo-dodec-2-en-1, 4-olide (3). The structures were confirmed using HRESIMS and NMR. 
Figure 12. Butenolides isolated from SM8 (1-3) and avenolide, a butenolide produced by S. avermitilis.

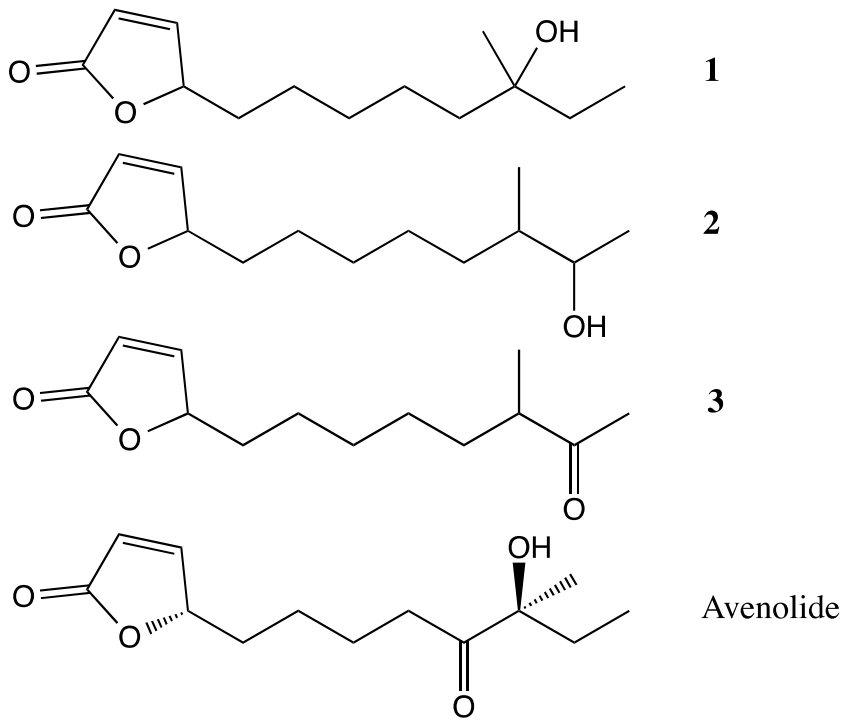

Butenolide 1 has also been isolated from a Streptomyces sp. cultivated from a Mediterranean sponge Tethya sp. and has been proven to have inhibitory activity against Trypanosoma brucei brucei [41]. These butenolides were also present in the antifungal fractions, although the antifungal activity can be attributed to the antimycins that were likewise present in the fractions as purified fractions of these butenolides were found to lack antifungal activity. Some furanones have quorum signaling activity [42] and it is possible that these butenolides synthesized by SM8 play a regulatory role. The butenolide avenolide (Figure 12) has been shown to have a role in the regulation of antibiotic production in S. avermitilis [43]. Butenolides are similar in structure to the $\gamma$-butyrolactones, the main differences being the position of the side chain, the presence of a double bond in the butenolides, and the presence of an alcohol functional group on the $\gamma$-butyrolactones. $\gamma$-Butyrolactones are common signaling molecules in Streptomyces, with analogous functions to $N$-acyl homoserine lactone (AHL) signaling molecules of Gram-negative bacteria [44], and the butenolide avenolide has been shown to interact with regulatory proteins that are closely related to those involved in regulation via $\gamma$-butyrolactones. In the avenolide-producing organism $S$. avermitilis, a proposed biosynthetic gene cluster was identified consisting of a regulatory gene, a cytochrome P450 hydroxylase gene and an acyl-CoA oxidase gene. The same arrangement of genes was not present in the SM8 genome, and at present the biosynthetic pathway of this class of compounds is unknown. Butenolides have also been isolated from sponges [45] and research has shown that furanones may be used by eukaryotic host organisms to interfere with prokaryotic signaling, thereby regulating the colonies they play host to [46,47].

Volatile butenolides and other furanone derivatives have previously been identified as products of antimycin degradation [48] and thus were not found in Streptomyces mutants lacking the antimycin gene cluster. The three butenolides isolated from SM8 differed from these degradation products in that, unlike the volatile butenolides, they lacked the 2-alkyl group and possessed an alkyl chain ratherthan a methyl group on C-4. These compounds evidently arose from a different biosynthetic pathway unrelated to the antimycin pathway as their production was not diminished in the $\Delta a n t C$ mutant. 


\subsection{Comparison of Endosymbiont and Host Sponge Metabolic Profiles}

\subsubsection{LC-HRESIMS Comparison}

The LC-HRESIMS spectra of the Streptomyces SM8 and H. simulans extracts, both prepared as $1 \mathrm{mg} \cdot \mathrm{mL}^{-1}$ in $70: 30$ methanol:dichloromethane were processed using a customized version of MZmine 2.10 [49]. After peak picking, alignment of the peaks allowed the generation of a scatter plot (Figure 13) to compare the metabolites present in each extract. Metabolites falling within the diagonal are present in approximately the same concentration in both extracts whereas those outside the diagonal are more prominent in the sample stated in the corresponding axis. Most antimycin compounds were found only in the SM8 extract, which is unsurprising as antimycins are bacterial products. However, antimycin Alb was detected in the sponge extract, albeit at a lower intensity than in the SM8 extract. Deisovaleryl-antimycin A3 (Figure 11) was found in higher concentrations in the sponge extract than the bacterial extract. From our studies it is clear that Streptomyces strain SM8 has the capacity to produce different antimycin metabolites in different conditions and it is possible that the growth conditions in the sponge favored the production of this particular antimycin. It is also possible that the isovaleryl side group is removed from the antimycin as a result of sponge metabolism, resulting in the high level of this compound in the $H$. simulans extract. The butenolides $\mathbf{1}$ and $\mathbf{2}$ were present in low quantities in the sponge extract, but butenolide $\mathbf{3}$ was found solely in the SM8 sample.

Figure 13. Scatter plot comparison of $H$. simulans ( $x$-axis) and SM8 ( $y$-axis) in the positive ionization mode. Metabolites identified as belonging to the antimycin family of compounds are highlighted in yellow whereas the isolated butenolides are highlighted in green. Although the differences in concentration are to be expected, the presence of common metabolites in the extracts confirmed that some metabolites in the H. simulans extract are products of its symbiont, SM8.

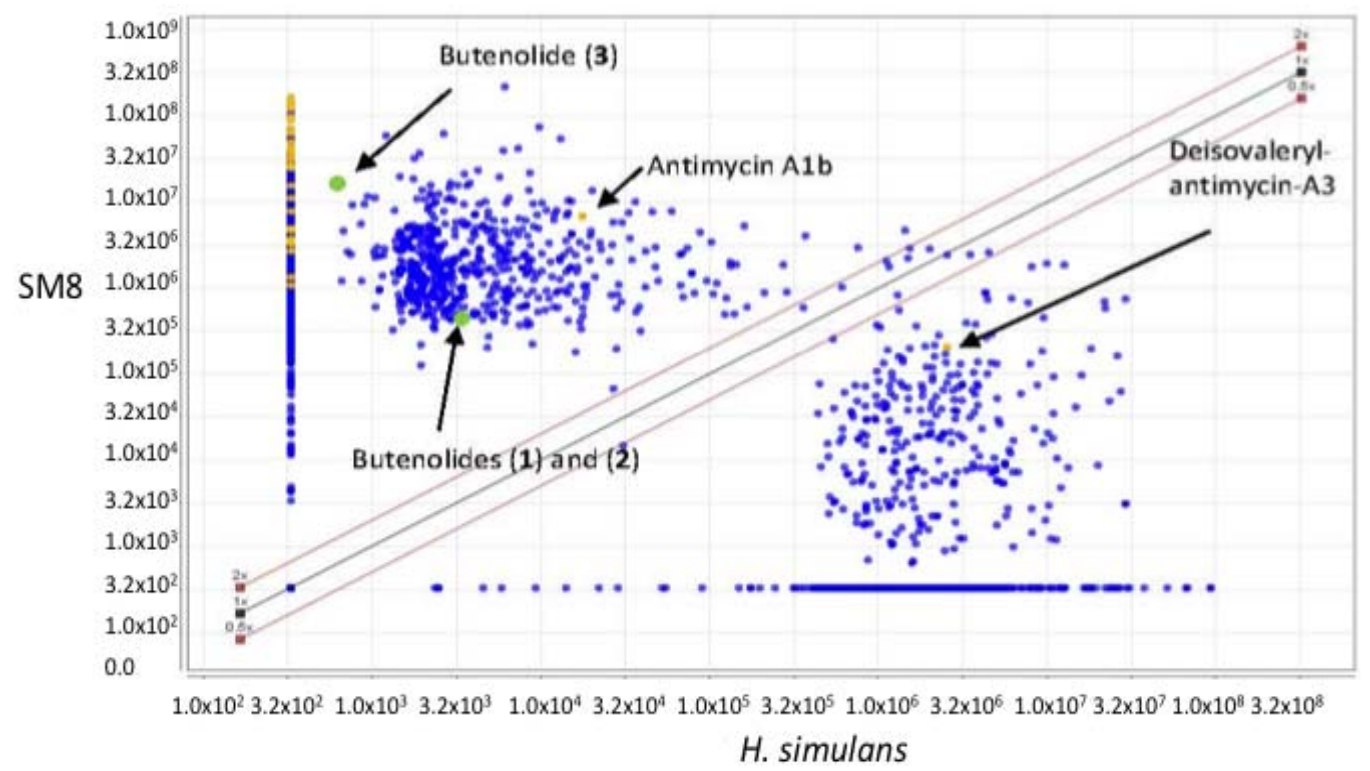

Dereplication of the other metabolites common to both samples resulted in highlighting compounds isolated from a variety of sources, including sponges, bacteria, fungi, algae and other marine 
invertebrates. Figure 14 shows the expansion of the scatter plot in the ESI positive mode with the focus on compounds that are present in both samples and have a peak area greater than $1.0 \times 10^{5}$. No peaks with this peak area fell within the diagonal in the ESI negative mode. The metabolites are colored according to their source. The identified metabolites falling within the diagonal can be seen in Table 5 . The majority of these compounds have previously been isolated from Streptomyces sp. Thus, although these compounds were not isolated from SM8, the fact that these metabolites are produced by the same genus gives credence to their putative identifications.

Figure 14. Common metabolites in $H$. simulans ( $x$-axis) and Streptomyces SM8 ( $y$-axis) extracts with peak areas $\geq 1.0 \times 10^{5}$ in the positive ionization mode. Blue circles are unidentified; black circles are metabolites previously isolated from fungi, algae and other marine invertebrates; green circles are those previously isolated from sponges and/or bacteria; red circles are those isolated from Haliclona sp.

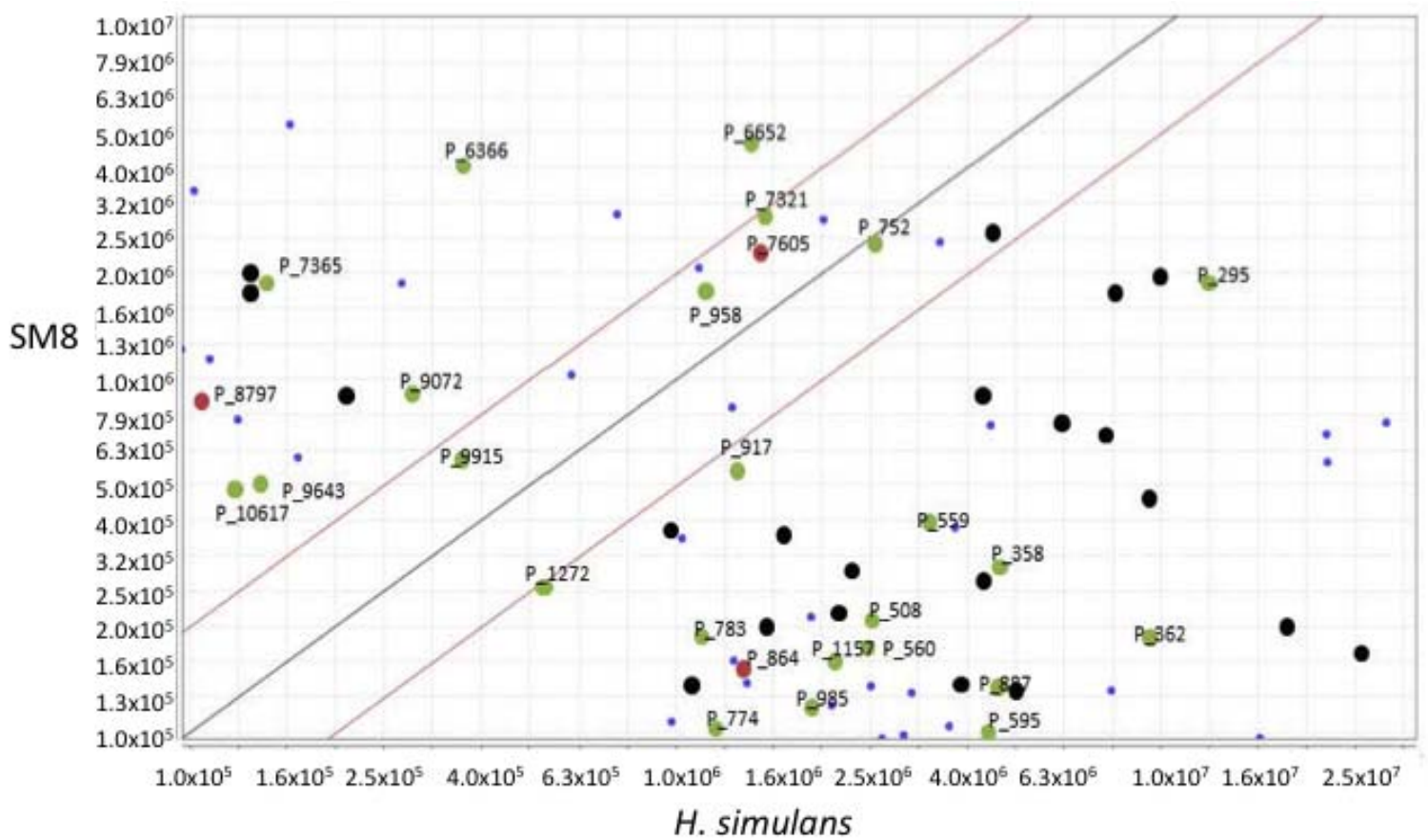

The scatter plot illustrates that there are metabolites which are common between the sponge and its endosymbiont. This highlights the relationship between the two organisms; that is, it confirms that Streptomyces SM8 is likely to be a true symbiont of $H$. simulans. Several of the putative compounds in Table 5 above are small MW peptides and are possibly produced by one of the NRPS gene clusters present in Streptomyces SM8, while the compound with Mol_ID P 9915 (9-(4-aminophenyl)-7-hydroxy-2, 4,6-trimethyl-9-oxo-non-2-enoic acid) is a truncated version of candicidin that could have arisen as a shunt product of the candicidin pathway or as a degradation product. Although a candicidin gene cluster was present in Streptomyces SM8, intact candicidin was not detected in any of the culture broths. It is possible that some metabolites produced by Streptomyces SM8 are utilized by $H$. simulans for defensive or regulatory purposes; as previously mentioned, antimycins can act as both antifungal and fish deterrent compounds, and the butenolides may function as signaling molecules. 
Table 5. Common metabolites present in the extracts of $H$. simulans and Streptomyces SM8 (positive ionization). The compounds were putatively identified using the AntiMarin 2012 database. Only those from sponges or bacteria are included in the table.

\begin{tabular}{|c|c|c|c|c|c|}
\hline Mol_ID & $m / z$ & RT (min) & Formula & Name & Source \\
\hline P_752 & 295.1649 & \multirow{3}{*}{4.00} & \multirow{3}{*}{$\mathrm{C}_{15} \mathrm{H}_{22} \mathrm{~N}_{2} \mathrm{O}_{4}$} & 1328-3; Cyclocarbamide B & [B] Streptoverticillium sp. \\
\hline \multirow{2}{*}{ P_7321 } & \multirow{2}{*}{295.1641} & & & $(2 S, 3 R)-3$-Amino-2-hydroxy-1- & [B] Streptomyces neyagawaensis SL-387 \\
\hline & & & & phenylbutanoyl-L-valine & + DL-3-amino-3-phenylpropionic \\
\hline \multirow{4}{*}{ P_7605 } & \multirow{4}{*}{206.0812} & \multirow{4}{*}{6.62} & \multirow{4}{*}{$\mathrm{C}_{11} \mathrm{H}_{11} \mathrm{NO}_{3}$} & \multirow{2}{*}{ Indole-3-lactic acid } & [B] Streptomyces sp. L083; marine \\
\hline & & & & & Streptomyces sp. 7919 \\
\hline & & & & 1-(3-Indolyl)-2,3-dihydroxypropan-1-one & [B] Streptomyces violaceus, marine \\
\hline & & & & 1-Hydroxymethyl-7-methoxyisoquinolinol & Porifera Haliclona sp \\
\hline \multirow{4}{*}{ P_958 } & \multirow{4}{*}{243.1338} & \multirow{4}{*}{5.27} & \multirow{4}{*}{$\mathrm{C}_{11} \mathrm{H}_{18} \mathrm{~N}_{2} \mathrm{O}_{4}$} & Bicycloamid; & [B] Streptomyces albus Tue 2031 \\
\hline & & & & 3,7-Dihydroxy-cis,cis-1,8-nonadiene-1, & [B] marine actinomycete B 1758 \\
\hline & & & & 9-dicarboxylic acid diamide & \\
\hline & & & & & Porifera Asteropus sp. \\
\hline \multirow{3}{*}{ P_9915 } & \multirow{3}{*}{320.1852} & \multirow{3}{*}{14.93} & \multirow{3}{*}{$\mathrm{C}_{18} \mathrm{H}_{25} \mathrm{NO}_{4}$} & 9-(4-Aminophenyl)-7-hydroxy-2,4, & \multirow{3}{*}{ [B] Streptomyces griseus subsp. } \\
\hline & & & & 6-trimethyl-9-oxo-non-2-enoic acid & \\
\hline & & & & & \\
\hline
\end{tabular}

\subsubsection{GC-MS Comparison}

The ethyl acetate-soluble components of $H$. simulans and Streptomyces SM8 were compared using GC-MS. For dereplication purposes as well as to exhaust all information about the investigated extracts, GCMS data also was collected in parallel to those found by LC-HRESIMS. In this case, the results can be compared taking advantage of the capability of each ionization technique in relation to the chemistry of the compounds being detected. Figure 15 shows the GC-MS chromatograms of the two samples. It is evident that the sponge has peaks that elute later from the column. These compounds were most likely less volatile and thus require a higher temperature to elute.

The GC-MS peaks were dereplicated using the online NIST11 library. All those present in the $H$. simulans sample at 15-17 min were all detected to be steroids. Through their respective EI (electron impact) mass spectrum, identified compounds dereplicated from the library had matching factor scores $\geq 800$ for the SI (similarity index) and RSI (reversed search index) while the (Prob) probability score were $\geq 70$. Although three bioactive steroids were earlier isolated from $H$. simulans [50], the four identified steroids $4,5,6$, and $\mathbf{7}$ were not among those previously isolated. This indicated that steroids $\mathbf{4}, \mathbf{5}, \mathbf{6}$, and 7 may be present in the sponge in smaller quantities. All four have previously been found in marine sources including sponges. The previously isolated steroids had short side chains and were more polar; thus they may not be volatile enough to be detected by GC-MS without derivatization. The elution capability was also influenced by the structural features such as the number of carbons on the side chain, the degree of saturation and location of double bonds in the cyclopentanoperhydrophenanthrene ring and/or in the side chain whether their orientation is cis or trans, and the number of methyl groups on C-4 [51-53]. For example, sterols with an ethyl group on C-24 in the side chain as in stigmasta-5, 24(28)-dien-3-ol (7) had longer retention times than those with a methyl group as in ergosta-5, 22-dien-3-ol (6). In addition, sterols with a double bond on C-22 elute earlier as found in cholesta-5, 
22-dien-3-ol (4) than sterols with no double bonds in the side chain like cholesterol (5). The elution order thus observed was: cholesta-5,22-dien-3-ol (4) < cholesterol (5) < ergosta-5,22-dien-3-ol (6) < stigmasta-5,24(28)-dien-3-ol (7).

Figure 15. GC-MS chromatograms of H. simulans (top) and Streptomyces SM8 (bottom).

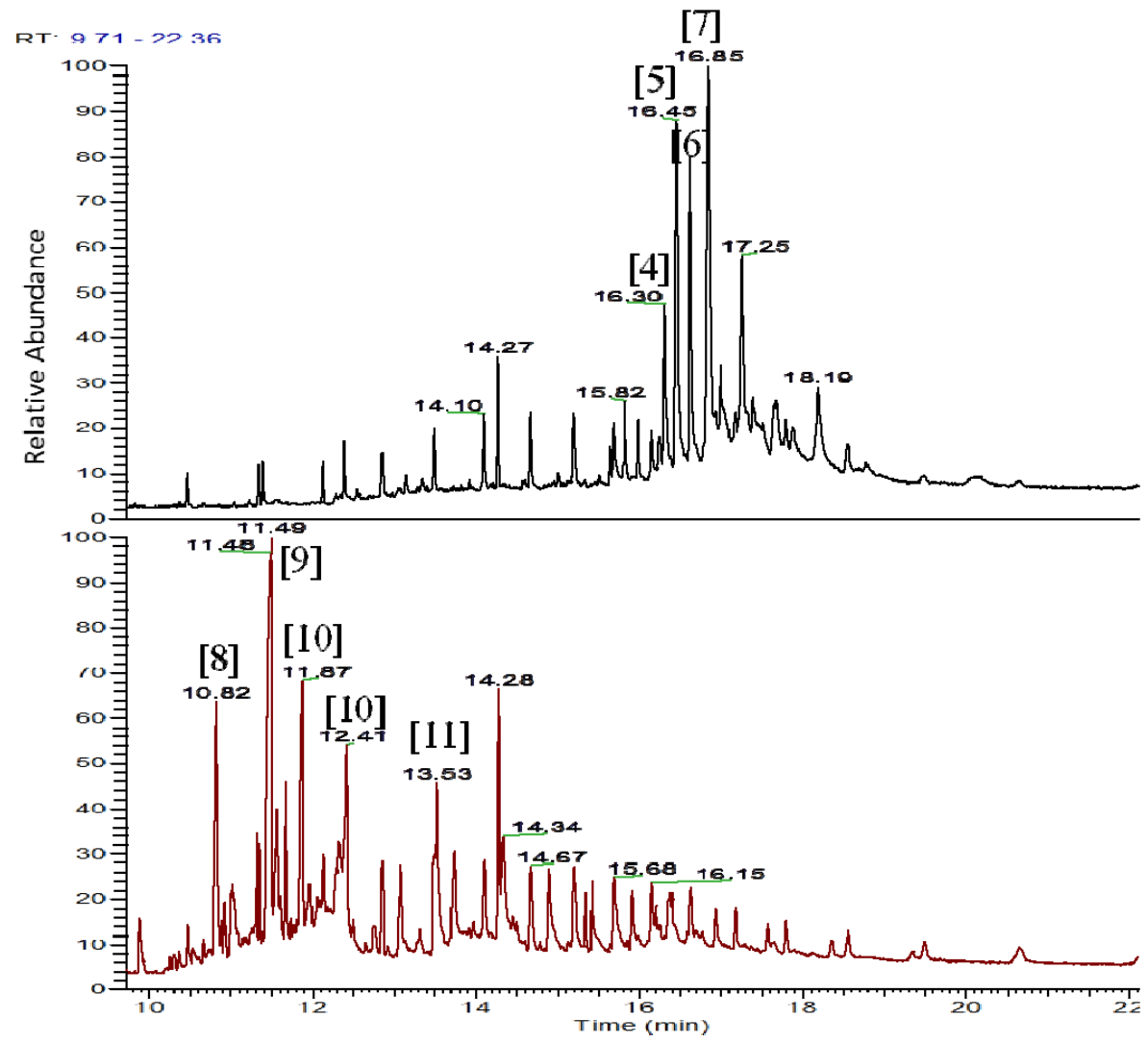

Figure 16. Metabolites putatively dereplicated from the $H$. simulans and Streptomyces SM8 extracts using the NIST11 GC-MS libraries.

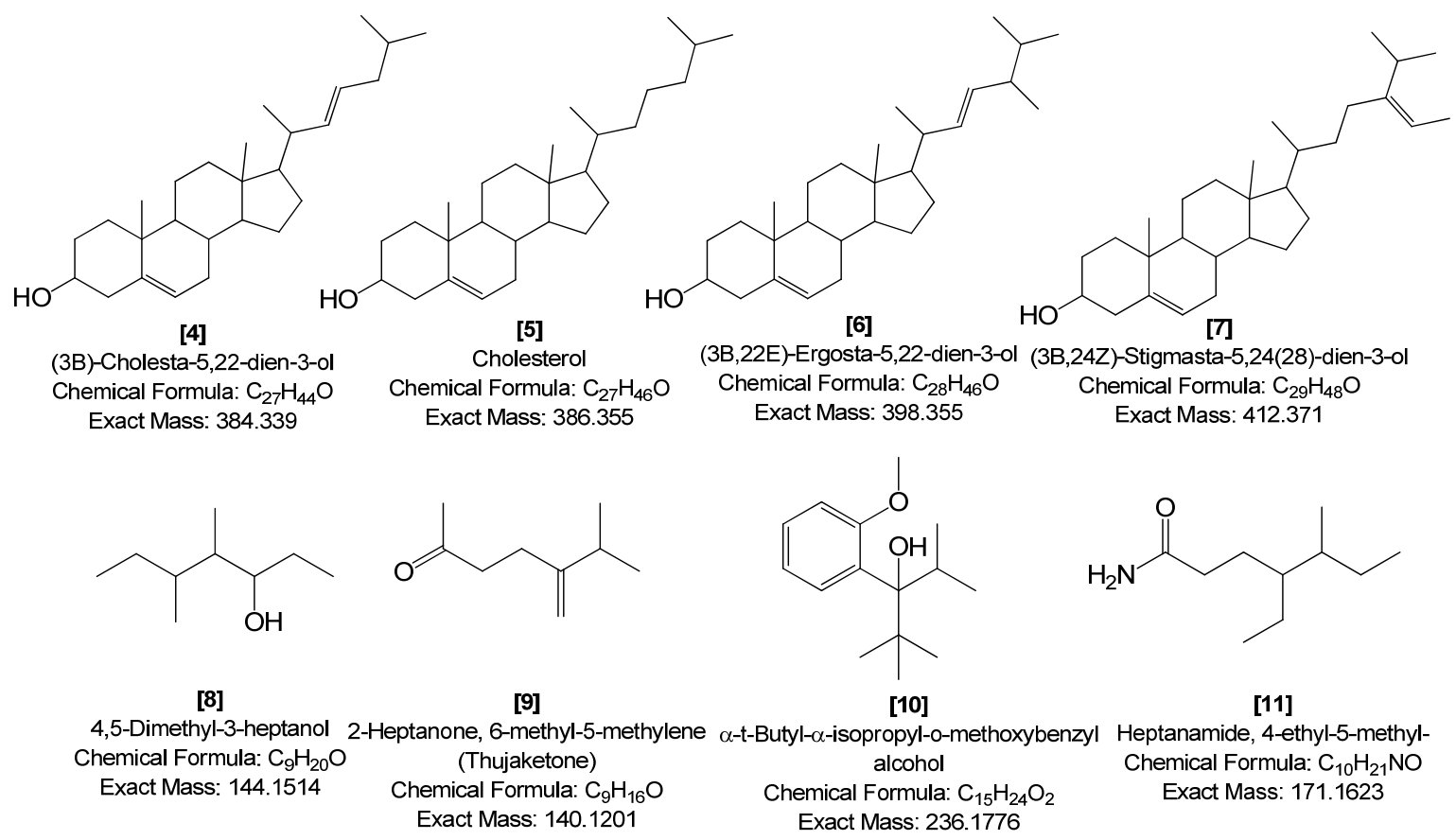


In contrast to the sponge, the Streptomyces SM8 extract contained smaller molecules that had retention times of 10-13 min (Figures 15 and 16). However, the dereplicated "hits" (8, 9, 10, and 11) for the bacterial extracts gave poor matching scores, although the RSI factor were $\geq 800$, the SI factors were ranging between 200 and 600 while the probability scores were less than 30. Among these "hits" were thujaketone (9) and 4-ethyl-5-methyl-heptanamide (11). Thujaketone (9) is commonly obtained from plants. Conversely, its carbon skeleton is the same as the side chain of ergosterol [54]. 4-Ethyl-5-methyl-heptanamide (11) has previously been isolated from a terrestrial Streptomyces sp. [55] as well as from freshwater green alga [56]. The MS spectrum for this compound, a fatty acid amide, contained a peak at $\mathrm{m} / \mathrm{z} 59$ that is characteristic of aliphatic primary amides [56].

\section{Experimental Section}

\subsection{Culture of Streptomyces Strain SM8}

Streptomyces strain SM8 was isolated from the marine sponge Haliclona simulans as described previously [8]. For preparation of extracts, seed cultures $(50 \mathrm{~mL}$ broth in $250 \mathrm{~mL}$ conical flasks) of 410-SW broth (modified from [57]) (10 g glucose, $10 \mathrm{~g}$ glycerol, $15 \mathrm{~g}$ casamino acids, $5 \mathrm{~g}$ oatmeal, $10 \mathrm{~g}$ peptone, $5 \mathrm{~g}$ yeast extract, $1 \mathrm{~g}$ calcium carbonate, $33.3 \mathrm{~g}$ Instant Ocean ${ }^{\circledR}$ per liter of $\mathrm{dH}_{2} \mathrm{O}$ ) were inoculated with spores and incubated for 7 days at $28{ }^{\circ} \mathrm{C}$ with shaking at $200 \mathrm{rpm}$. These seed cultures were used to inoculate production flasks $(50 \mathrm{~mL}$ broth in $250 \mathrm{~mL}$ conical flasks or $800 \mathrm{~mL}$ broth in $2 \mathrm{~L}$ conical flasks) containing OM-SW broth (modified from [55]) (20 g oatmeal, $33.3 \mathrm{~g}$ Instant Ocean ${ }^{\circledR}$ per liter of $\mathrm{dH}_{2} \mathrm{O}$ ) or SYP-SW broth (10 g starch, $4 \mathrm{~g}$ yeast extract, $2 \mathrm{~g}$ peptone, $33.3 \mathrm{~g}$ Instant Ocean ${ }^{\circledR}$ per liter of $\mathrm{dH}_{2} \mathrm{O}$ ) at a 1:50 dilution and incubated for 12 days at $28{ }^{\circ} \mathrm{C}$ in a shaking incubator at $200 \mathrm{rpm}$. All extracts were prepared in triplicates.

\subsection{Preparation of Active Crude Extracts of Streptomyces Strain SM8}

A total of $16 \mathrm{~L}$ of the culture broth was clarified by centrifugation at $12,000 \times \mathrm{g}$ for $15 \mathrm{~min}$ in a Beckmann Coulter Avanti J-26 centrifuge (Pasadena, CA, USA). The supernatant was passed through Miracloth (Calbiochem, San Diego, CA, USA) to remove the debris. Initial compound extraction was performed by adding $70 \mathrm{~g}$ of prewashed amberlite XAD-16 per liter of culture and incubating overnight with shaking. The resin was collected by filtration and the extraction was repeated. Active compounds were then eluted from the resin using an equal volume of methanol with stirring for $2 \mathrm{~h}$. The methanol washing step was repeated several times until the eluate was colorless. The extract was then concentrated by evaporation and desalted by liquid-liquid partitioning with ethyl acetate and water. The ethyl acetate fraction was then evaporated to dryness. All extracts were prepared in triplicates.

\subsection{Bioassays}

Crude extracts and purified fractions in triplicates were assayed for antimicrobial activity using the following indicator strains: Candida albicans SC5314, Candida glabrata CBS138, Saccharomyces cerevisiae BY4741, Kluyveromyces marxianus CBS6556, Aspergillus fumigatus Af293, Bacillus subtilis IE32, Escherichia coli 12210, Staphylococcus aureus NC000949 and Pseudomonas aeruginosa PA01. 
Antifungal [58] and antibacterial [59] activities were determined using resazurin based assays performed with dilution series of extracts in 96 well microtiter plates.

\subsection{Genomic Sequencing}

\subsubsection{Extraction of Genomic DNA}

Streptomyces strain SM8 was grown in SYP-SW broth for three days at $28^{\circ} \mathrm{C}$ in a shaker incubator at $200 \mathrm{rpm}$ and the genomic DNA was extracted using the cetyltrimethylammonium bromide (CTAB) method [60]. DNA was quantified using a NanoDrop spectrophotometer (Thermo Scientific, Bremen, Germany) and analyzed by agarose gel electrophoresis. The concentration of the DNA was adjusted to $200 \mathrm{ng} \cdot \mu \mathrm{L}^{-1}$ for genome sequencing.

\subsubsection{Genome Sequencing and Analyses}

Genomic sequencing was carried out by the Centre for Genomic Research, University of Liverpool. The nucleotide sequence was generated from a fragment library using the GS FLX Titanium system (Roche 454 Sequencing, Branford, CT, USA) resulting in 229,280 reads and 94,668,678 bp, giving approximately 10 -fold coverage of the genome. The genome was assembled using the Meta-assembler program hosted by Community cyberinfrastructure for Advanced Microbial Ecology Research and Analysis (CAMERA 2.0) [61] and the reads were quality filtered resulting in 539 contigs. The genome was annotated using the Prodigal pipeline hosted by IMG/ER [62]. Secondary metabolite genes were additionally identified using antiSMASH [63] that rapidly identifies a whole range of known secondary metabolite compound classes. Contigs identified as containing secondary metabolism genes were used as queries to scan for functional similarities both in Clusters of Orthologous Groups of proteins (COGs) and Pfam databases in IMG/ER. The IMG/ER has about $88 \mathrm{COG}$ proteins and 52 Protein families (Pfam) relating to secondary metabolism and synthesis, catabolism and transport. The protein sequences corresponding to the secondary metabolite genes were searched in BLASTp [64]. The sequences were also compared to other Streptomyces species in the NCBI database using BLAST to identify the closest homologue. The genome sequence is deposited at GenBank with accession number PRJNA180938.

\subsection{Identification and Isolation of Bioactive Metabolites of SM8}

\subsubsection{Reverse Phase MPLC of Small Scale SM8 Extract}

The SM8 extract, weighing $343.7 \mathrm{mg}$, was subjected to medium pressure liquid chromatography (MPLC) using a Sepacore ${ }^{\circledR}$ chromatography system (Büchi Labortechnik, Basel, Switzerland) consisting of two C 605 pump modules, a C 620 control unit over a VersaPak C-18 (Spherical) $23 \times 53 \mathrm{~mm}$ (15 g) column. The column was eluted with water (A) and methanol (B) using the following stepwise gradient: 1\% B (5 min), 1\%-50\% B (30 min), 50\% B (5 min), 50\%-100\% B (25 min). The flow rate was $10 \mathrm{~mL} \cdot \mathrm{min}^{-1}$. Fractions were collected every $15 \mathrm{~s}$. A total of 264 fractions were obtained. These were pooled according to their LC-MS chromatograms as measured by the low resolution Finnigan LCQ-Deca mass spectrometer coupled to an HPLC (series 1100) from Agilent (Santa Clara, CA, USA). 


\subsubsection{NMR and LC-HRESIMS of Active SM8 Fractions}

Following activity assays, the active fractions were analyzed by NMR using a Jeol-LA400 FT-NMR spectrometer system (JEOL Ltd., Tokyo, Japan) with an AS400 magnet (Oxford Instruments, Inghilterra, UK) at $400 \mathrm{MHz}$ for ${ }^{1} \mathrm{H}$ and $100 \mathrm{MHz}$ for ${ }^{13} \mathrm{C}$, using a Pulse Field Gradient "Autotune" 40TH5AT/FG broadband high sensitivity probe (JEOL Ltd., Tokyo, Japan) to accept $5 \mathrm{~mm}$ tubes. High-resolution mass spectrometry was carried out on a Dionex UltiMate-3000 (DIONEX, Sunnyvale, CA, USA) coupled to an Exactive-Orbitrap (Thermo Scientific, Bremen, Germany). The column was an ACE 5 C18 $75 \times 3.0 \mathrm{~mm}$ column from Hichrom Ltd, Reading, UK. Compounds were eluted with a flow rate of $300 \mu \mathrm{L} \cdot \mathrm{min}^{-1}$ using water (A) and acetonitrile (B), both of which contained $0.1 \%$ formic acid, by a gradient starting with $10 \% \mathrm{~B}$ and increasing to $100 \% \mathrm{~B}$ in $30 \mathrm{~min}$. The mobile phase was maintained at $100 \% \mathrm{~B}$ for $5 \mathrm{~min}$, after which the column was equilibrated with $10 \% \mathrm{~B}$. The injection volume was $10 \mu \mathrm{L}$ and the tray temperature was maintained at $12{ }^{\circ} \mathrm{C}$. High resolution mass spectrometry was carried out in both positive and negative ESI ionization modes with a spray voltage of $4.5 \mathrm{kV}$ and capillary temperature of $268{ }^{\circ} \mathrm{C}$. Spray voltage at $4.5 \mathrm{kV}$, spray current set $10.67 \mu \mathrm{A}$, and capillary voltage at $30 \mathrm{~V}$. The mass range was acquired from $\mathrm{m} / \mathrm{z} 150$ to 1500 .

Multi-fragmentation $\left(\mathrm{MS}^{n}\right)$ experiments were accomplished for the positive ionization mode on an Orbitrap analyser, CID (The collision-induced dissociation) was utilized with a normalized collision energy of $35 \%$, activation Q of $0.250 \mathrm{~ms}$, and activation time of $30.000 \mathrm{~ms}$ applied on ions of most intense, 2nd most intense, and 3rd most intense peaks for MS2, MS3, and MS4, respectively at an isolation width of 3 microns with 5 microscans. Resolution was at $15,000 \mathrm{~m} / \Delta \mathrm{m} 50 \%$, while the minimum ion signal threshold was set to 500. Fragment mass tolerance for molecular formula detection was set to $\pm 5 \mathrm{ppm}$.

Data mining was performed using MZmine 2.10 [49]. The following parameters were used:

The chromatograms were first cropped to 0.5-38.0 min using the crop filter under the dataset filtering function. The centroid mass detector was used for peak detection with the noise level set to $1.0 \times 10^{5}$ and the MS level set to 1 . The chromatogram builder function was set to a minimum time span of $0.2 \mathrm{~min}$, minimum height of $1.0 \times 10^{5}$ and $\mathrm{m} / \mathrm{z}$ tolerance of $0.001 \mathrm{~m} / \mathrm{z}$ or $5.0 \mathrm{ppm}$. For chromatogram deconvolution the algorithm used was the local minimum search. The chromatographic threshold was set to $90.0 \%$. The search minimum in RT range was $0.4 \mathrm{~min}$, minimum relative height was $5.0 \%$, minimum absolute height was $3.0 \times 10^{5}$, minimum ratio of peak top/edge was 2 and the peak duration range was $0.3-5.0 \mathrm{~min}$. Isotopes were detected using the isotopic peaks grouper. The $\mathrm{m} / \mathrm{z}$ tolerance was $0.001 \mathrm{~m} / \mathrm{z}$ or $5.0 \mathrm{ppm}$, RT tolerance was 0.2 absolute (min), the maximum charge was 2 and the representative isotope used was the most intense. Retention time normalization was performed using the RT normalizer. Again, $\mathrm{m} / \mathrm{z}$ tolerance was $0.001 \mathrm{~m} / \mathrm{z}$ or $5.0 \mathrm{ppm}$ while the RT tolerance and the minimum standard intensity were set to $5 \%$ (relative) and $5.0 \times 10^{3}$ respectively. The peak lists were all aligned using the join aligner $(\mathrm{m} / \mathrm{z}$ tolerance $0.001 \mathrm{~m} / \mathrm{z}$ or $5.0 \mathrm{ppm}$, weight for $\mathrm{m} / \mathrm{z}$ : 20, RT tolerance: $5.0 \%$ relative, weight for RT: 20 ). The aligned peak list was gapfilled using the peak finder function (intensity tolerance: $1 \%, \mathrm{~m} / \mathrm{z}$ tolerance: $0.001 \mathrm{~m} / \mathrm{z}$ or $5.0 \mathrm{ppm}$, RT tolerance: $0.5 \mathrm{~min}$ ). An adduct search was performed with the RT tolerance set at 0.2 absolute ( $\mathrm{min}$ ), the $\mathrm{m} / \mathrm{z}$ tolerance at $0.001 \mathrm{~m} / \mathrm{z}$ or $5.0 \mathrm{ppm}$ and the maximum relative adduct peak height at $30 \%$. The adducts searched for were $\mathrm{Na}^{+}, \mathrm{K}^{+}, \mathrm{NH}_{4}{ }^{+}$and $\mathrm{ACN}+\mathrm{H}$. A complex search was also performed using $[\mathrm{M}+\mathrm{H}]^{+}$for the ESI 
positive mode and $[\mathrm{M}-\mathrm{H}]^{-}$for the ESI negative mode. The RT tolerance was set at 0.2 absolute (min), $\mathrm{m} / \mathrm{z}$ tolerance was kept at $0.001 \mathrm{~m} / \mathrm{z}$ or $5.0 \mathrm{ppm}$, and the maximum complex peak height was set at 50\%. A custom database search was then performed using the DNP 2012 database [65].

\subsubsection{Construction of SM8 antC Mutant}

To inactivate the antimycin gene cluster, a two-step gene deletion procedure was used [60]. Flanking regions from within the antC gene of approximately $1.4 \mathrm{~kb}$ were amplified using the High-Fidelity PCR kit (Roche, Basel, Switzerland). Primer pairs (Table 6) were designed to amplify upstream and downstream regions with restriction sites engineered suitable for cloning into the Streptomyces/E. coli shuttle vector pKC1139 [66]. PCR products from antC1-F/antC1-R and antC2-F/ antC2-R were cloned into pJET1.2/blunt using the Fermentas PCR cloning kit. Following sequence verification the antC flanking regions were purified as HindIII-XbaI and XbaI-EcoRI fragments, respectively and cloned into HindIII and EcoRI digested pKC1139 resulting in pKC1139A1A2.

Table 6. Primers designed for the construction of the antC deletion strain. Engineered restriction sites are shown underlined.

\begin{tabular}{cc}
\hline & \multicolumn{1}{c}{ Primer Sequences $\left(\mathbf{5}^{\prime}-\mathbf{3}^{\prime}\right)$} \\
\hline antC1-F & TATATAAAGCTTGGACGGCTACAGCTACAAGC \\
antC1-R & TATATATCTAGAATGAGGTATGCGGTGTCGTA \\
antC2-F & TATATATCTAGAGAGGTGGTTCGTGGAGGAG \\
antC2-R & TATATAEAATTCTGACGATGATGACGTCCTTG \\
\hline
\end{tabular}

pKC1139A1A2 was conjugated to Streptomyces sp. SM8 strain. Competent cells of the dam-/dcm-E. coli C2925/pUZ8002 were transformed to apramycin resistance with pKC1139A1A2. The helper plasmid pUZ8002 can supply transfer functions to oriT-carrying plasmids, such as pKC1139. Cultures of E. coli C2925/pUZ8002/pKC1139A1A2 were grown in $10 \mathrm{~mL}$ of LB containing $25 \mu \mathrm{g}$ kanamycin $/ \mathrm{mL}, 25 \mu \mathrm{g}$ chloramphenicol $/ \mathrm{mL}$ and $50 \mu \mathrm{g}$ apramycin $/ \mathrm{mL}$ overnight at $37{ }^{\circ} \mathrm{C}$. The overnight culture was diluted $(1: 10)$ in LB containing the aforementioned antibiotics and grown at $37{ }^{\circ} \mathrm{C}$ to an OD600 of 0.5. The cells were washed twice with an equal volume of LB to remove antibiotics and resuspended in 0.1 vol. of LB. Approximately, $10^{8}$ spores of the SM8 strain were added to $500 \mu \mathrm{L}$ of $2 \times$ YT broth $(1.6 \%$ peptone, $1 \%$ yeast extract, and $0.5 \% \mathrm{NaCl})$ and subjected to heat shock at $50{ }^{\circ} \mathrm{C}$ for $10 \mathrm{~min}, 0.5 \mathrm{~mL}$ of E. coli cells were added and the spores were briefly mixed. The pellet was resuspended and plated onto MS-SW agar (mannitol $20 \mathrm{~g}$, soya flour $20 \mathrm{~g}$, agar $20 \mathrm{~g}$, Instant Ocean $^{\circledR} 33 \mathrm{~g}$ made up to $1 \mathrm{~L}$ with $\mathrm{dH}_{2} \mathrm{O}$ ). Following incubation at $28{ }^{\circ} \mathrm{C}$ for $20 \mathrm{~h}$ the plates were overlayered with $1 \mathrm{~mL}$ antibiotic solution containing $0.5 \mathrm{mg}$ nalidixic acid and $2 \mathrm{mg}$ apramycin. These plates were further incubated at $28{ }^{\circ} \mathrm{C}$ until potential exconjugants were observed. The transconjugants were plated on to SYP-SW media containing nalidixic acid $25 \mu \mathrm{g} \cdot \mathrm{mL}^{-1}$ and apramycin $100 \mu \mathrm{g} \cdot \mathrm{mL}^{-1}$ [60] and incubated at $28^{\circ} \mathrm{C}$ until exconjugants were observed.

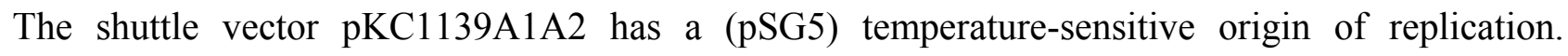
In Streptomyces it can replicate only at temperatures between 28 and $30{ }^{\circ} \mathrm{C}$. When potential exconjugants were plated on to SYP-SW containing apramycin $100 \mu \mathrm{g} \cdot \mathrm{mg}^{-1}$ and incubated at $37{ }^{\circ} \mathrm{C}$, the vector stops replicating and apramycin resistance is only maintained when the plasmid is integrated 
onto the chromosome by homologous recombination. Apramycin resistant recombinant clones were allowed to sporulate on SYP-SW agar at $37^{\circ} \mathrm{C}$. Spores were collected and plated out to single colonies at $28{ }^{\circ} \mathrm{C}$ without selection. Single colonies were then picked and screened for the loss of apramycin resistance, a phenotype indicating that the plasmid has been lost with deletion of the antC gene.

The wild-type and mutant SM8 extracts were compared to an antimycin A standard (Antimycin A, from Streptomyces sp.) purchased from Sigma-Aldrich Co (St. Louis, MO, USA). The LC-HRMS analysis was performed on a Finnigan Surveyor system coupled to a Thermo-Finnigan LTQ Orbitrap system using the same column and method stated in section 3.5.2.

\subsubsection{Isolation of Compounds from Large Scale SM8 Culture}

The large-scale SM8 extract, weighing $810.3 \mathrm{mg}$, was fractionated using a Sephadex ${ }^{\circledR}$ LH20 column (Pharmacia, Stockholm, Sweden) with methanol as the mobile phase at a flow rate of $1 \mathrm{~mL} / 15$ $\min \left(0.067 \mathrm{~mL} \cdot \mathrm{min}^{-1}\right)$ and a collection volume of $1 \mathrm{~mL} /$ test tube. 169 fractions were collected. An aliquot of each tube was subjected to activity assays. The active fractions were subsequently pooled based on their activity and similarities in the TLC.

The pooled fraction 127-156 displayed prominent antifungal activity. This fraction was further purified using a silica column with the following solvent systems: 95:5 hexane:ethyl acetate, 90:10 hexane:ethyl acetate, 80:20 hexane:ethyl acetate, and 50:50 hexane:ethyl acetate, followed by washing of the column with 70:30 dichloromethane:methanol, 50:50 acetone:methanol and 100\% methanol. The fractions and purified compounds were subsequently subjected to activity assays and analyzed using NMR and LC-HRESIMS.

4,10-Dihydroxy-10-methyl-dodec-2-en-1,4-olide (1): $\mathrm{Rf} 0.56$ (80:20 MeOH: $\mathrm{H}_{2} \mathrm{O}, \mathrm{C}-18$ silica gel), blue-violet with anisaldehyde-sulfuric acid; $\mathrm{UV}_{\max } 219.0(\mathrm{MeOH}) ;{ }^{1} \mathrm{H}$ NMR (400 MHz, DMSO) $\delta 7.84(1 \mathrm{H}, \mathrm{dd}, J=5.7,1.4 \mathrm{~Hz}, \mathrm{H}-3), 6.20$ (1 H, dd, $J=5.7,1.8 \mathrm{~Hz}, \mathrm{H}-2), 5.15$ (1 H, m, H-4), 1.71 (1 H, m, H-5a), 1.55 (1 H, dd, $J=14.3,6.9 \mathrm{~Hz}, \mathrm{H}-5 \mathrm{~b}), 1.33$ (2 H, q, $\left.J=7.5 \mathrm{~Hz}, \mathrm{H}_{2}-11\right), 1.33\left(2 \mathrm{H}, \mathrm{H}_{2}-6\right)$, 1.28 (brd. s), 0.98 (3 H, s, $\left.\mathrm{CH}_{3}-13\right), 0.79\left(3 \mathrm{H}, \mathrm{t}, J=7.5 \mathrm{~Hz}, \mathrm{CH}_{3}-12\right) ;{ }^{13} \mathrm{C}$ NMR (100 MHz, DMSO) $\delta 173.6(1-\mathrm{C}=\mathrm{O}), 159.3(3-\mathrm{CH}), 120.8(2-\mathrm{CH}), 83.7(4-\mathrm{CH}), 71.2(10-\mathrm{C}), 41.5\left(9-\mathrm{CH}_{2}\right), 34.4\left(5-\mathrm{CH}_{2}\right)$, $34.4\left(11-\mathrm{CH}_{2}\right), 30.1\left(7-\mathrm{CH}_{2}\right), 26.9\left(13-\mathrm{CH}_{3}\right), 25.0\left(6-\mathrm{CH}_{2}\right), 23.8\left(8-\mathrm{CH}_{2}\right), 8.8\left(12-\mathrm{CH}_{3}\right)$; HRESIMS: Calculated: $m / z$ 227.1602 [M+H] ${ }^{+}$; Experimental: $m / z$ 227.1637 [M+ H] $]^{+}$.

4,11-Dihydroxy-10-methyl-dodec-2-en-1,4-olide (2): Rf 0.56 (80:20 MeOH: $\mathrm{H}_{2} \mathrm{O}, \mathrm{C}-18$ silica gel), blue-violet with anisaldehyde-sulfuric acid; $\mathrm{UV}_{\max } 219.0(\mathrm{MeOH}) ;{ }^{1} \mathrm{H}$ NMR (400 MHz, DMSO) $\delta 7.84(1 \mathrm{H}, \mathrm{dd}, J=5.7,1.4 \mathrm{~Hz}, \mathrm{H}-3), 6.20$ (1 H, dd, $J=5.7,1.8 \mathrm{~Hz}, \mathrm{H}-2), 5.15$ (1 H, m, H-4), 3.42 (2 H, m, $\mathrm{H}_{2}-11$ ), 1.71 (1 H, m, H-5a), 1.55 (1 H, dd, $\left.J=14.3,6.9 \mathrm{~Hz}, \mathrm{H}-5 \mathrm{~b}\right), 1.33$ (2 H, H2-6), 1.28 (brd. s), $0.96\left(3 \mathrm{H}, \mathrm{d}, J=6.3 \mathrm{~Hz}, \mathrm{CH}_{3}-12\right), 0.77\left(3 \mathrm{H}, \mathrm{td} J=6.6 \mathrm{~Hz}, \mathrm{CH}_{3}-13\right) ;{ }^{13} \mathrm{C}$ NMR $(100 \mathrm{MHz}, \mathrm{DMSO}) \delta$ $173.6(1-\mathrm{C}=\mathrm{O}), 159.3(3-\mathrm{CH}), 120.8(2-\mathrm{CH}), 83.7(4-\mathrm{CH}), 70.0\left(11-\mathrm{CH}_{2}\right), 41.0(10-\mathrm{CH}), 34.4\left(5-\mathrm{CH}_{2}\right)$, $32.8\left(9-\mathrm{CH}_{2}\right), 30.1\left(7-\mathrm{CH}_{2}\right), 27.2\left(8-\mathrm{CH}_{2}\right), 25.0\left(6-\mathrm{CH}_{2}\right), 19.9\left(12-\mathrm{CH}_{3}\right), 15.1\left(13-\mathrm{CH}_{3}\right)$; HRESIMS: Calculated: $m / z$ 227.1602 [M+H] $]^{+}$; Experimental: $m / z$ 227.1637 [M+H] $]^{+}$

4-Hydroxy-10-methyl-11-oxo-dodec-2-en-1,4-olide (3): $\mathrm{UV}_{\max } 223.0$ (MeOH); ${ }^{1} \mathrm{H} \mathrm{NMR}$ (400 MHz, DMSO) $\delta 7.84(1 \mathrm{H}, \mathrm{d}, J=5.9 \mathrm{~Hz}, \mathrm{H}-3), 6.20(1 \mathrm{H}, \mathrm{dd}, J=5.6,1.9 \mathrm{~Hz}, \mathrm{H}-2), 5.14(1 \mathrm{H}, \mathrm{dd}$, $J=7.2,5.1 \mathrm{~Hz}, \mathrm{H}-4), 2.09\left(3 \mathrm{H}, \mathrm{s}, \mathrm{CH}_{3}-12\right), 1.70(1 \mathrm{H}, \mathrm{m}, \mathrm{H}-5 \mathrm{a}), 1.55(1 \mathrm{H}, \mathrm{dd}, J=14.9,7.4 \mathrm{~Hz}$, 
H-5b), 1.27 (m), 0.98 (3 H, d, $J=6.9 \mathrm{~Hz}, \mathrm{CH}_{3}-13$ ); HRESIMS: Calculated: $\mathrm{m} / \mathrm{z} 225.1446[\mathrm{M}+\mathrm{H}]^{+}$; Experimental: $m / z 225.1486[\mathrm{M}+\mathrm{H}]^{+}$.

\subsection{Comparison of Endosymbiont and Host Sponge Metabolic Profiles}

\subsubsection{LC-HRESIMS Analysis of Extracts}

An acetone-methanol extract of $H$. simulans was de-salted with gradient elution through HP20 using water and methanol followed by 50:50 acetone:methanol and 100\% methanol washes. An aliquot was taken from each fraction aside from the 100\% water and the 90:10 aliquots, which contained the most salt. The pooled aliquot was dried down and resuspended in 10:90 $\mathrm{H}_{2} \mathrm{O}: \mathrm{MeOH}$ to a final concentration of $1 \mathrm{mg} \cdot \mathrm{mL}^{-1}$ for LC-MS. The SM8 sample was taken from the larger-scale extract and was dissolved in methanol. The samples were run on an Accela HPLC system coupled to a Thermo Scientific Exactive-Orbitrap using the same column and method stated in section 3.5.2. The results were compared using MZmine 2.10 [49].

\subsubsection{GC-MS Analysis of Extracts}

The ethyl acetate-soluble portions of the extracts of $H$. simulans and SM8 were run on a Focus GC-DSQ II from Thermo Scientific (Thermo Fisher Scientific (Bremen) GmbH, Bremen, Germany). The column, InertCap 1MS (ID: $0.25 \mathrm{~mm}$, length: $30 \mathrm{~m}$, df: $0.25 \mu \mathrm{m}$ ) was from GL Sciences Inc., Tokyo, Japan. The oven temperature was set at $80{ }^{\circ} \mathrm{C}$ for $1 \mathrm{~min}$ after which the temperature was increased at a rate of $15^{\circ} \mathrm{min}^{-1}$ until $200^{\circ} \mathrm{C}$. This temperature was maintained for 15 min after which it was again increased at a rate of $5^{\circ} \mathrm{min}^{-1}$ until the final temperature of $320{ }^{\circ} \mathrm{C}$. This was held for 10 min until the end of the run. The base temperature of the SSL was $250{ }^{\circ} \mathrm{C}$ whereas the MS transfer line was maintained at $320^{\circ} \mathrm{C}$. The electron ionization (EI) source temperature of the DSQ II mass spectrometer was set to $250{ }^{\circ} \mathrm{C}$. The injection was performed in the splitless mode with helium as the constant carrier gas at a flow rate of $1.5 \mathrm{~mL} \cdot \mathrm{min}^{-1}$ and mass scan range at $\mathrm{m} / \mathrm{z} 50.0-800.0$.

\section{Conclusions}

The combined metabolomic and genomic approach used in this study resulted in the rapid identification of antimycins and polyhydroxylated saturated fatty acids as major antifungal and antibacterial metabolites of Streptomyces SM8, respectively. Bioassay-guided fractionation of large scale SM8 extracts also highlighted the presence of the antifungal antimycin family of compounds. Three butenolide compounds were also isolated and identified and while the biosynthetic origin of these compounds is currently unknown, the genome sequence of Streptomyces SM8 provides a genetic framework with which to study their biosynthesis and their potential role in regulation of gene expression. Likewise, as the SM8 $\Delta a n t C$ mutant retained some antifungal activity, larger scale cultivation of these mutants can lead to the identification of potentially novel antifungal metabolites with genomic correlation to secondary metabolism gene clusters.

Comparison of the extracts of the host sponge $H$. simulans and its endosymbiont, Streptomyces SM8, using high resolution LC-MS revealed the presence of metabolites, including antimycins and a putative candicidin shunt or degradation product common to both extracts. This confirmed that SM8 is 
indeed associated with $H$. simulans and that bioactive components produced by Streptomyces SM8 are present in the sponge tissue, thus providing further evidence of the potential for microbial symbionts to provide their sponge host with a chemical defense system.

\section{Acknowledgments}

C.V. would like to acknowledge the scholarship funded by the Scottish Overseas Research Students Award Scheme (SORSAS). This work was supported by the Royal Society Equipment Grant (115773: Marine symbionts and terrestrial endophytes for industrial biotechnology of novel antibiotics) awarded to R.E.-E. as well as the Beaufort Marine Biodiscovery Research award funded by the Irish Government under the National Development Plan (2007-2013) and the PharmaSea project funded by the EU Seventh Framework Programme (Contract number 312184, [67]) awarded to A.D.W.D. The metabolomics work was developed under SeaBioTech funded by the European Commission within its FP7 Programme, under the thematic area KBBE.2012.3.2-01 with Contract Number 311932 [68] awarded to R.E.-E.

\section{Author Contributions}

Conceived and designed the metabolomics profiling and chemical study: CV, TZ, REE. Performed the metabolomics profiling and chemical isolation experiments: CV. Macro development for metabolomics profiling: TZ. Analyzed the metabolomics profile and structure elucidation work: CV, REE. Wrote the part of the paper on the metabolomics profiling: CV, REE. Conceived and designed the genomic and bioassay experiments: LMM, JK, FOG, JPM, ADWD. Performed the genomic and bioassay experiments: LMM, JK. Analyzed the genomic data: LMM, JK, COB. Wrote the part of the paper on the genomic study: LMM, JK, ADWD

\section{Conflicts of Interest}

The authors declare no conflict of interest.

\section{References}

1. Blunt, J.W.; Copp, B.R.; Munro, M.H.; Northcote, P.T.; Prinsep, M.R. Marine natural products. Nat. Prod. Rep. 2004, 21, 1-49.

2. Blunt, J.W.; Copp, B.R.; Keyzers, R.A.; Munro, M.H.; Prinsep, M.R. Marine natural products. Nat. Prod. Rep. 2014, 31, 160-258.

3. Taylor, M.; Radax, R.; Steger, D.; Wagner, M. Sponge-associated microorganisms: Evolution, ecology, and biotechnological potential. Microbiol. Mol. Biol. Rev. 2007, 71, 295-347.

4. Schmitz, F.; Vanderah, D.; Hollenbeak, K.; Enwall, C.; Gopichand, Y.; Sengupta, P.; Hossain, M.; Vanderhelm, D. Metabolites from the marine sponge Tedania ignis. A new atisanediol and several known diketopiperazines. J. Org. Chem. 1983, 48, 3941-3945.

5. Stierle, A.; Cardellina, J.; Singleton, F. A marine micrococcus produces metabolites ascribed to the sponge Tedania ignis. Experientia 1988, 44, 1021. 
6. Gunasekera, S.; Gunasekera, M.; McCarthy, P. Discodermide-A new bioactive macrocyclic lactam from the marine sponge Discodermia dissoluta. J. Org. Chem. 1991, 56, 4830-4833.

7. Ito, S.; Hirata, Y. The structure of ikarugamycin, an acyltetramic acid antibiotic possessing a unique asymmetric-hydrindacene skeleton. Bull. Chem. Soc. Jpn. 1977, 50, 1813-1820.

8. Kennedy, J.; Baker, P.; Piper, C.; Cotter, P.; Walsh, M.; Mooij, M.; Bourke, M.; Rea, M.; O'Connor, P.; Ross, R.; et al. Isolation and analysis of bacteria with antimicrobial activities from the marine sponge Haliclona simulans collected from irish waters. Mar. Biotechnol. 2009, 11, 384-396.

9. Khan, S.; Tamura, T.; Takagi, M.; Shin-ya, K. Streptomyces tateyamensis sp. nov., Streptomyces marinus sp. nov. and Streptomyces haliclonae s. nov., isolated from the marine sponge Haliclona sp. Int. J. Syst. Evol. Microbiol. 2010, 60, 2775-2779.

10. Khan, S.; Komaki, H.; Motohashi, K.; Kozone, I.; Mukai, A.; Takagi, M.; Shin-ya, K. Streptomyces associated with a marine sponge Haliclona sp.; biosynthetic genes for secondary metabolites and products. Environ. Microbiol. 2011, 13, 391-403.

11. Jiang, S.; Sun, W.; Chen, M.; Dai, S.; Zhang, L.; Liu, Y.; Lee, K.; Li, X. Diversity of culturable actinobacteria isolated from marine sponge Haliclona sp. Antonie Van Leeuwenhoek 2007, 92, 405-416.

12. El-Tarabily, K.A.; Sykes, M.L.; Kurtböke, I.D.; Hardy, G.E.S.J.; Barbosa, A.M.; Dekker, R.F.H. Synergistic effects of a cellulase-producing Micromonospora carbonacea and an antibiotic-producing Streptomyces violascens on the suppression of Phytophthora cinnamomi root rot of Banksia grandis. Can. J. Bot. 1996, 74, 618-624.

13. Jonsson, A.; Torstensson, N. Protease inhibitors from Streptomyces violascens. 2. Production of the inhibitors. Arch. Mikrobiol. 1972, 83, 71-77.

14. Tomioka, H.; Kagawa, M.; Nakamura, S. Some enzymatic properties of 3beta-hydroxysteroid oxidase produced by Streptomyces violascens. J. Biochem. 1976, 79, 903-915.

15. Dettmer, K.; Aronov, P.A.; Hammock, B.D. Mass spectrometry-based metabolomics. Mass Spectrom. Rev. 2007, 26, 51-78.

16. Rochfort, S. Metabolomics reviewed: A new "Omics” Platform technology for systems biology and implications for natural products research. J. Nat. Prod. 2005, 68, 1813-1820.

17. Seipke, R.F.; Grüschow, S.; Goss, R.J.; Hutchings, M.I. Isolating antifungals from fungus-growing ant symbionts using a genome-guided chemistry approach. Methods Enzymol. 2012, 517, 47-70.

18. Seipke, R.F.; Barke, J.; Brearley, C.; Hill, L.; Yu, D.W.; Goss, R.J.; Hutchings, M.I. A single Streptomyces symbiont makes multiple antifungals to support the fungus farming ant Acromyrmex octospinosus. PLoS One 2011, 6, e22028.

19. Udwary, D.W.; Zeigler, L.; Asolkar, R.N.; Singan, V.; Lapidus, A.; Fenical, W.; Jensen, P.R.; Moore, B.S. Genome sequencing reveals complex secondary metabolome in the marine actinomycete Salinispora tropica. Proc. Natl. Acad. Sci. USA 2007, 104, 10376-10381.

20. Tawfike, A.F.; Viegelmann, C.; Edrada-Ebel, R. Metabolomics and dereplication strategies in natural products. Methods Mol. Biol. 2013, 1055, 227-244. 
21. Abdelmohsen, U.R.; Cheng, C.; Viegelmann, C.; Zhang, T.; Grkovic, T.; Ahmed, S.; Quinn, R.J.; Hentschel, U.; Edrada-Ebel, R. Dereplication strategies for targeted isolation of new antitrypanosomal actinosporins a and $\mathrm{b}$ from a marine sponge associated-actinokineospora sp. Mar. Drugs 2014, 12, 1220-1244.

22. Nishida, F.; Mori, Y.; Isobe, S.; Furuse, T.; Suzuki, M.; Meevootisom, V.; Flegel, T.; Thebtaranonth, Y. Structures of deacetyl glykenins-a, b and c, glycosidic antibiotics from Basidiomycetes sp. Tetrahedron Lett. 1988, 29, 5287-5290.

23. Paradis, E.; Goyer, C.; Hodge, N.; Hogue, R.; Stall, R.; Beaulieu, C. Fatty acid and protein profiles of streptomyces scabies strains isolated in eastern canada. Int. J. Syst. Bacteriol. 1994, 44, 561-564.

24. Sjögren, J.; Magnusson, J.; Broberg, A.; Schnürer, J.; Kenne, L. Antifungal 3-hydroxy fatty acids from lactobacillus plantarum milab 14. Appl. Environ. Microbiol. 2003, 69, 7554-7557.

25. Kitahara, T.; Koyama, N.; Matsuda, J.; Aoyama, Y.; Hirakata, Y.; Kamihira, S.; Kohno, S.; Nakashima, M.; Sasaki, H. Antimicrobial activity of saturated fatty acids and fatty amines against methicillin-resistant Staphylococcus aureus. Biol. Pharm. Bull. 2004, 27, 1321-1326.

26. Girisham, S.; Reddy, S.; Rao, G.; Rao, P. Metabolites from the fermentation of Ulocladium botrytis. J. Nat. Prod. 1986, 49, 548-549.

27. Turner, W.B.; Aldridge, D.C. Fungal Metabolites II; Academic Press Inc. (London) Ltd.: London, UK, 1983.

28. Takesako, K.; Beppu, T. Studies on new antifungal antibiotics, guanidylfungins a and b. I. Taxonomy, fermentation, isolation and characterization. J. Antibiot. 1984, 37, 1161-1169.

29. Takesako, K.; Beppu, T. Studies on new antifungal antibiotics, guanidylfungins a and b. II. Structure elucidation and biosynthesis. J. Antibiot. 1984, 37, 1170-1186.

30. Dunshee, B.; Leben, C.; Keitt, G.; Strong, F. The isolation and properties of antimycin a. J. Am. Chem. Soc. 1949, 71, 2436-2437.

31. Liu, W.; Strong, F. The chemistry of antimycin a. 6. Separation and properties of antimycin a subcomponents. J. Am. Chem. Soc. 1959, 81, 4387-4390.

32. Van Tamelen, E.E.; Dickie, J.P.; Loomans, M.E.; Dewey, R.S.; Strong, F.M. The chemistry of antimycin a. X. Structure of the antimycins. J. Am. Chem. Soc. 1961, 83, 1639-1646.

33. Kluepfel, D.; Sehgal, S.; Vezina, C. Antimycin a components. 1. Isolation and biological activity. J. Antibiot. (Tokyo) 1970, 23, 75-80.

34. Shiomi, K.; Hatae, K.; Hatano, H.; Matsumoto, A.; Takahashi, Y.; Jiang, C.; Tomoda, H.; Kobayashi, S.; Tanaka, H.; Omura, S. A new antibiotic, antimycin a(9), produced by Streptomyces sp. k01-0031. J. Antibiot. (Tokyo) 2005, 58, 74-78.

35. Rehacek, Z.; Ramankutty, M.; Kozova, J. Respiratory chain of antimycin a-producing Streptomyces antibioticus. Appl. Microbiol. 1968, 16, 29-32.

36. Abidi, S.L.; Ha, S.C.; Rosen, R.T. Liquid chromatography-thermospray mass spectrometric study of $n$-acylamino dilactones and 4-butyrolactones derived from antimycin a. J. Chromatogr. 1990, 552, 179-194.

37. Neft, N.; Farley, T. Conditions influencing antimycin production by a Streptomyces species grown in chemically defined medium. Antimicrob. Agents Chemother. 1972, 1, 274-276. 
38. Yan, Y.; Zhang, L.; Ito, T.; Qu, X.; Asakawa, Y.; Awakawa, T.; Abe, I.; Liu, W. Biosynthetic pathway for high structural diversity of a common dilactone core in antimycin production. Org. Lett. 2012, 14, 4142-4145.

39. Seipke, R.; Patrick, E.; Hutchings, M. Regulation of antimycin biosynthesis by the orphan ECF RNA polymerase sigma factor $\sigma^{\text {anta }}$. Peer J. 2014, 2, e253.

40. Mukku, V.; Speitling, M.; Laatsch, H.; Helmke, E. New butenolides from two marine streptomycetes. J. Nat. Prod. 2000, 63, 1570-1572.

41. Pimentel-Elardo, S.; Kozytska, S.; Bugni, T.; Ireland, C.; Moll, H.; Hentschel, U. Anti-parasitic compounds from Streptomyces sp strains isolated from mediterranean sponges. Mar. Drugs 2010, 8, 373-380.

42. Martinelli, D.; Grossmann, G.; Sequin, U.; Brandl, H.; Bachofen, R. Effects of natural and chemically synthesized furanones on quorum sensing in Chromobacterium violaceum. BMC Microbiol. 2004, 4, 25.

43. Kitani, S.; Miyamoto, K.T.; Takamatsu, S.; Herawati, E.; Iguchi, H.; Nishitomi, K.; Uchida, M.; Nagamitsu, T.; Omura, S.; Ikeda, H.; et al. Avenolide, a streptomyces hormone controlling antibiotic production in Streptomyces avermitilis. Proc. Natl. Acad. Sci. USA 2011, 108, 16410-16415.

44. Horinouchi, S.; Beppu, T. Autoregulatory factors and communication in actinomycetes. Annu. Rev. Microbiol. 1992, 46, 377-398.

45. Faulkner, D. Marine natural products. Nat. Prod. Rep. 2002, 19, 1-48.

46. Givskov, M.; DeNys, R.; Manefield, M.; Gram, L.; Maximilien, R.; Eberl, L.; Molin, S.; Steinberg, P.; Kjelleberg, S. Eukaryotic interference with homoserine lactone-mediated prokaryotic signaling. J. Bacteriol. 1996, 178, 6618-6622.

47. Kjelleberg, S.; Steinberg, P.; Givskov, M.; Gram, L.; Manefield, M.; deNys, R. Do marine natural products interfere with prokaryotic ahl regulatory systems? Aquat. Microb. Ecol. 1997, 13, 85-93.

48. Riclea, R.; Aigle, B.; Leblond, P.; Schoenian, I.; Spiteller, D.; Dickschat, J.S. Volatile lactones from streptomycetes arise via the antimycin biosynthetic pathway. Chembiochem 2012, 13, 1635-1644.

49. Sourceforge Project Website. Available online: http://sourceforge.net/projects/mzmine/ (accessed on 22 April 2012).

50. Viegelmann, C.; Parker, J.; Ooi, T.; Clements, C.; Abbott, G.; Young, L.; Kennedy, J.; Dobson, A.D.W.; Edrada-Ebel, R. Isolation and identification of antitrypanosomal and antimycobacterial active steroids from the sponge haliclona simulans. Mar. Drugs 2014, 12, 2937-2952.

51. Abidi, S.L. Chromatographic analysis of plant sterols in foods and vegetable oils. J. Chromatogr. A 2001, 935, 173-201.

52. Patterson, G.W. Relation between structure and retention time of sterols in gas chromatography. Anal. Chem. 1971, 43, 1165-1170.

53. Thompson, R.H.; Patterson, G.W.; Thompson, M.; Slover, H.T. Separation of pairs of C-24 epimeric sterols by glass capillary gas liquid chromatography. Lipids 1981, 16, 694-699.

54. Werner, J.; Bogert, M.T. The synthesis from thujaketone of some new hydroterpenoids. J. Org. Chem. 1938, 3, 578-587. 
55. Abdalla, M.A.; Win, H.Y.; Islam, M.T.; von Tiedemann, A.; Schüffler, A.; Laatsch, H. Khatmiamycin, a motility inhibitor and zoosporicide against the grapevine downy mildew pathogen Plasmopara viticola from Streptomyces sp. Ank313. J. Antibiot. (Tokyo) 2011, 64, 655-659.

56. Dembitsky, V.M.; Shkrob, I.; Rozentsvet, O.A. Fatty acid amides from freshwater green alga Rhizoclonium hieroglyphicum. Phytochemistry 2000, 54, 965-967.

57. Goodfellow, M.; Fiedler, H.P. A guide to successful bioprospecting: Informed by actinobacterial systematics. Antonie Van Leeuwenhoek 2010, 98, 119-142.

58. Liu, M.; Seidel, V.; Katerere, D.R.; Gray, A.I. Colorimetric broth microdilution method for the antifungal screening of plant extracts against yeasts. Methods 2007, 42, 325-329.

59. Sarker, S.D.; Nahar, L.; Kumarasamy, Y. Microtitre plate-based antibacterial assay incorporating resazurin as an indicator of cell growth, and its application in the in vitro antibacterial screening of phytochemicals. Methods 2007, 42, 321-324.

60. Kieser, T.; Bibb, M.; Buttner, M.; Chater, K.; Hopwood, D. Practical Streptomyces Genetics; John Innes Foundation: Norwick, UK, 2000.

61. Sun, S.; Chen, J.; Li, W.; Altintas, I.; Lin, A.; Peltier, S.; Stocks, K.; Allen, E.E.; Ellisman, M.; Grethe, J.; et al. Community cyberinfrastructure for advanced microbial ecology research and analysis: The camera resource. Nucleic Acids Res. 2011, 39, D546-D551.

62. Markowitz, V.M.; Mavromatis, K.; Ivanova, N.N.; Chen, I.M.; Chu, K.; Kyrpides, N.C. IMG ER: A system for microbial genome annotation expert review and curation. Bioinformatics 2009, 25, 2271-2278.

63. Medema, M.H.; Blin, K.; Cimermancic, P.; de Jager, V.; Zakrzewski, P.; Fischbach, M.A.; Weber, T.; Takano, E.; Breitling, R. Antismash: Rapid identification, annotation and analysis of secondary metabolite biosynthesis gene clusters in bacterial and fungal genome sequences. Nucleic Acids Res. 2011, 39, W339-W346.

64. Altschul, S.F.; Gish, W.; Miller, W.; Myers, E.W.; Lipman, D.J. Basic local alignment search tool. J. Mol. Biol. 1990, 215, 403-410.

65. Dictionary of Natural Products Version 21.2; Taylor and Francis Group: Boca Raton, FL, USA, 2012.

66. Paget, M.S.; Chamberlin, L.; Atrih, A.; Foster, S.J.; Buttner, M.J. Evidence that the extracytoplasmic function sigma factor sigmae is required for normal cell wall structure in Streptomyces coelicolor a3(2). J. Bacteriol. 1999, 181, 204-211.

67. PharmaSea. Available online: http://www.pharma-sea.eu (accessed on 25 March 2014).

68. SeaBioTech. Available online: http://spider.science.strath.ac.uk/seabiotech/ (accessed on 25 March 2014).

(C) 2014 by the authors; licensee MDPI, Basel, Switzerland. This article is an open access article distributed under the terms and conditions of the Creative Commons Attribution license (http://creativecommons.org/licenses/by/3.0/). 